NISTIR 6773

\title{
Infrared Absorptivity Temperature Dependence of Gas Phase Methanol and Sulfur Dioxide
}

P.M. Chu, G.C. Rhoderick, and P.A. Johnson

$Q C$

.456

No. 4773

2001

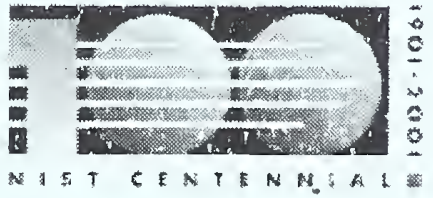

NLST

National Instifute of Standards and Technology

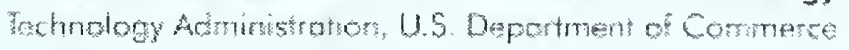



NISTIR 6773

\section{Infrared Absorptivity Temperature Dependence of Gas Phase Methanol and Sulfur Dioxide}

P.M. Chu, G.C. Rhoderick, and P.A. Johnson Analytical Chemistry Division Chemical Sciences and Technology Laboratory National Institnte of Standards and Technology' Gaithersburg, MD 20899-8393

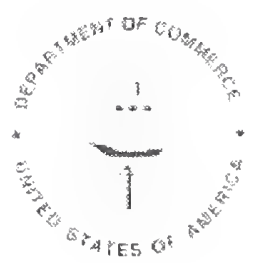

U.S. DEPARTMENT OF COMMERCE Donald L. Evans. Secretary

NATIONAL INSTITUTE OF STANDARDS AND TECHNOLOGY Karen II. Brown. Acting Director 



\section{Table of Contents}

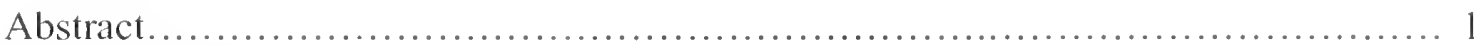

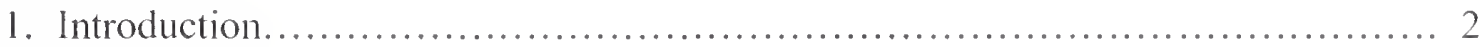

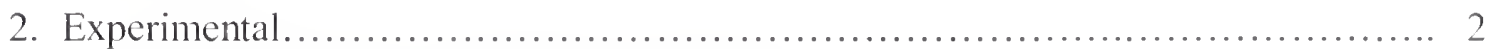

2.1 Gravimetric standards preparation.................................... 3

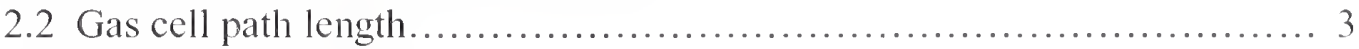

2.3 Gas cell temperature................................................. 4

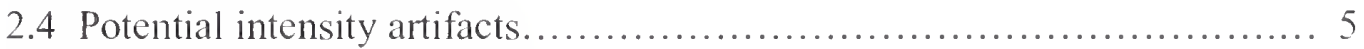

2.5 Sample emission effects............................................ 5

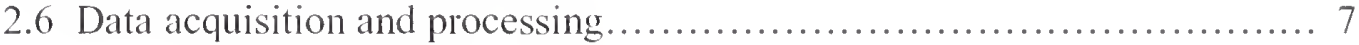

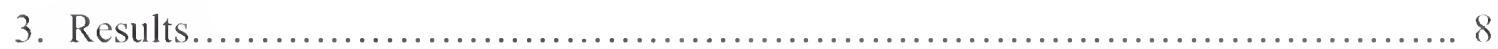

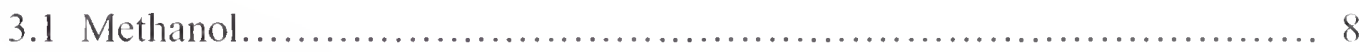

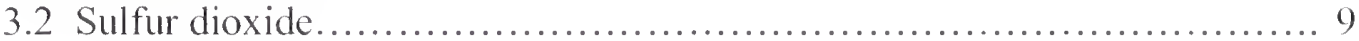

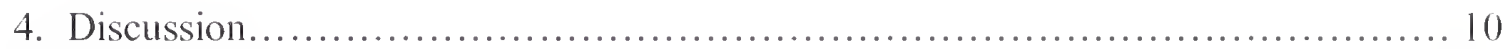

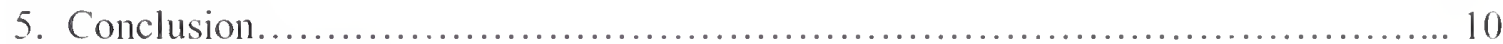

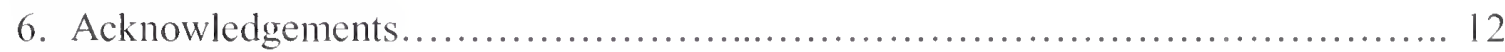

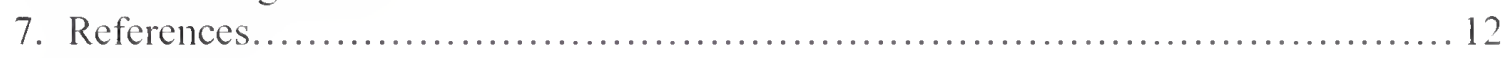

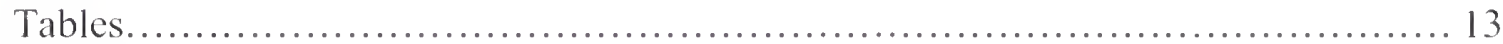

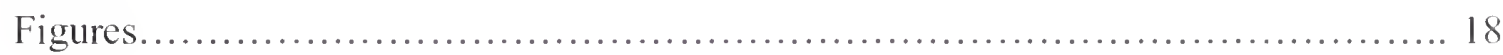




\begin{abstract}
The infrared absorptivity of industrially relevant compounds, methanol and sulfur dioxide, are evaluated for temperatures ranging from $25{ }^{\circ} \mathrm{C}$ to $200{ }^{\circ} \mathrm{C}$ at $25{ }^{\circ} \mathrm{C}$ increments using an FT spectrometer with NIST primary gravimetric standards. This project was initiated to provide quality-assured reference data for communities measuring stack emissions by passive FT-IR and other infrared-based technologies. In order to correct for the sample and sample cell emission effects, sample and reference data are acquired with the infrared source on and with the source off. The average relative expanded uncertainty for the uncorrected absorption coefficients is $2.0 \%$ for absorptivity values greater than $1 \times 10^{-4}(\mu \mathrm{mol} / \mathrm{mol})^{-1} \mathrm{~m}^{-1}$, excluding the sample emission bias. The average relative expanded uncertainty is $2.5 \%$ for the absorption coefficient data corrected for sample emission effects. The emission correction tracks the blackbody emission of the sample cell and is both wavelength- and temperature-dependent. For temperatures up to $200{ }^{\circ} \mathrm{C}$, there is no emission correction for bands at $2600 \mathrm{~cm}^{-1}$ and higher. In the fingerprint region, the emission correction becomes significant especially at temperatures above 100 ${ }^{\circ} \mathrm{C}$. At $200{ }^{\circ} \mathrm{C}$, the correction is approximately $10 \%$ for bands in the spectral region near $1000 \mathrm{~cm}^{-1}$. The magnitude of the emission correction depends on the design of the optical bench; therefore it is necessary to characterize the correction for each apparatus.
\end{abstract}

Keywords: infrared absorptivity, sample emission, temperature dependence, methanol, sulfur dioxide 


\section{INTRODUCTION}

Recent studies have shown that passive Fourier-transform infrared (FT-IR) spectroscopy is a viable method for stack gas emissions monitoring. [1] The inherent temperature contrast between stack plumes and the background facilitate the detection of IR signatures of vapor phase analytes. While the tempcrature differential between the ambient atmosphere and the stack emissions permit passive FT-IR measurements, the complex temperature profiles of stack emissions demand absorption coefficient data for the analytes at a wide range of temperatures to assure quantitative accuracy of open-air spectral evaluations. The National Institute of Standards and Technology (NIST) has an on-going program to develop a quality-assured quantitative database of infrared spectra, Standard Reference Database (SRD) 79, [2,3] to support infrared-based remote sensing technologies. SRD 79 was initially developed to address the data needs of the open-path FT-IR monitoring communities mcasuring hazardous air pollutants at ambient conditions.

To address the pressing data needs of communitics measuring stack emissions by passive FT-IR and other infrared-based technologies, NIST has measured absorption coefficients for industrially important target gases, sulfur dioxide and methanol, at tcmperatures ranging from $25^{\circ} \mathrm{C}$ to $200{ }^{\circ} \mathrm{C}$. This report summarizes the efforts to characterize the FTIR measurements at these elevated temperatures such as the sample emission and cell length changes and the absorption coefficient data obtained for gravimetric standards of sulfur dioxide and methanol.

\section{EXPERIMENTAL}

The basic approach to these measurements was similar to the protocol developed for the NIST SRD 79 program, which has been described in detail.[3] Briefly, several well characterized gravimetric standards were used to obtain a minimum of seven transmittance spectra for each compound at each temperature and at $0.12 \mathrm{~cm}^{-1}$ resolution. Absorption coefficient spectra, $a(v)$ were calculated from the transmittance spectra using the Beer's law relationship:

$$
I_{t}(\mathrm{v})=I_{0}(\mathrm{v}) 10^{-a(\mathrm{v}) \mathrm{cl}}
$$

where $I_{0}(\mathrm{~V})$ and $I_{\mathrm{t}}(\mathrm{V})$ denote the incident and transmitted light intensities and $c$ and $l$ represent the concentration and path length respectively. Uncertainties in the absorption coefficient were estimated from linear regressions of the transmittance data and considerations of other sources of uncertainties, such as detector non-linearities and, for these specific experiments, the sample cell and sample emission at higher temperatures. The target experimental parameters are listed in Table 1 and were choscn to provide a reasonable match to open-air spectral measurements based on discussions with end users. The final experimental parametcrs were based on balancing the target parameters with the absorbance signal for the fingerprint absorption bands within the atmospheric window and the concentration limitations of the gravimetric standards. 


\subsection{Gravimetric standards preparation}

For the current measurements, gravimetric methanol standards ranging from $10.73 \mu \mathrm{mol} / \mathrm{mol}$ to $415.6 \mu \mathrm{mol} / \mathrm{mol}$ were prepared at NIST using high-purity blended air. The concentrations and purity of the methanol-in-air standards were verified using gas chromatography with flame-ionization detection. [3] The concentration of the sulfur dioxide standards ranged from $48.9 \mu \mathrm{mol} / \mathrm{mol}$ to $3186 \mu \mathrm{mol} / \mathrm{mol}$. These $\mathrm{SO}_{2}$ standards were blended by a commercial company to NIST specifications and the concentration values were assigned by comparing the mixtures to NIST primary gravimetric standards using pulsed fluorescence to detect $\mathrm{SO}_{2}$. Since the long-term stability of sulfur dioxidein-air mixtures was not known, the $\mathrm{SO}_{2}$ standards were made with high-purity nitrogen. Table 2 lists the concentration and the expanded uncertainties for each methanol-in-air and sulfur dioxide-in-nitrogen standard.

\subsection{Gas cell path length}

In order to achieve a concentration path length product of up to $2500(\mu \mathrm{mol} / \mathrm{mol}) \mathrm{m}$, either a gas standard of significant concentration and/or a long path gas cell must be used. Since the vapor pressure of methanol limits the concentration of the standards, a compact, nickel coated aluminum, multi-pass cell from Nicolet equipped with a band heater, zinc selenide windows, and an insulation jacket was used for these measurements. ${ }^{\text {a }}$ The nominal path length and volume of the multi-pass cell was $2 \mathrm{~m}$ and $200 \mathrm{~mL}$, respectively.

To ascertain the true path length, interferometry was used to measure the radius of curvature $[4,5]$ of the cell mirrors, and the cell body dimensions were measured using a coordinate measuring machine. From these measurements, the radius of curvature and the standard uncertainty for the two objective mirrors were $(99.88 \pm 0.1) \mathrm{mm}$ and $(99.90$ $\pm 0.1) \mathrm{mm}$ and the radius of curvature of the field mirror was $(99.85 \pm 0.1) \mathrm{mm}$. The cell body dimensions confirmed that the field mirror was placed at the focal plane of the objective mirrors to within $\pm 0.2 \mathrm{~mm}$. The estimated average distance between each cell window and the surface of the field mirror was $6.805 \mathrm{~mm}$ with a maximum possible deviation of $(+1.0 /-0.5) \mathrm{mm}$. With 20 passes, the estimated total cell path length was $201.14 \mathrm{~cm}$ with an expanded relative uncertainty of $0.26 \%$ at room temperature.[6]

The room temperature path length of the multi-pass cell was verified by acquiring the room temperature absorption coefficient using the set of gravimetric methanol-in-air samples and using $(2.0114 \pm 0.005) \mathrm{m}$ as the cell path length. The integrated band intensity over $2690 \mathrm{~cm}^{-1}$ to $3160 \mathrm{~cm}^{-1}$ of the methanol-in-air absorption coefficient data was compared to the previous methanol-in-nitrogen measurements, published in NIST SRD 79.[2] The present integrated band intensity agreed with data in NIST SRD 79 to within $1.0 \%$, which is within the overall uncertainty of the measurements. No differences

\footnotetext{
${ }^{a}$ Certain commercial equipment, instruments, or materials are identified in this paper to foster understanding. Such identification does not imply recommendation or endorsement by the National Institute of Standards and Technology, nor does it imply that the materials or equipment identified are the best available for the purpose.
} 
in the integrated band intensities were expected or observed for the samples with nitrogen versus blended air as the balance gas.

Naturally, the cell path length changes as the aluminum parts of the cell body expand with increasing temperatures. Table 3 lists the nominal cell path lengths at each temperature calculated from the base path lengths at room temperature and the thermal expansion coefficient for aluminum, $23 \times 10^{-6}{ }^{\circ} \mathrm{C}^{-1}$.[7] There is a $0.4 \%$ change in the total cell path length when the cell temperature is increased from $25{ }^{\circ} \mathrm{C}$ to $200{ }^{\circ} \mathrm{C}$. Measurements were made with carbon monoxide to confirm the cell path length as a function of temperature. A complete analysis of these data should verify the temperature dependence of the cell path length.

\subsection{Gas cell temperature}

The gas cell was supplied with an iron/constantan (type J) thermocouple soldered to a washer that was bolted to one of the end flanges. To verify the cell temperatures, several $0.25 \mathrm{~mm}$ thick chromel/alumel (type $\mathrm{K}$ ) thermocouples were spot welded directly to the cell body. Using the type $\mathrm{J}$ thermocouple to control the cell temperature at $175^{\circ} \mathrm{C}$, the type $\mathrm{K}$ thermocouples indicated that the cell body was $218.5^{\circ} \mathrm{C}$. Since the type $\mathrm{K}$ thermocouples were in direct contact with the cell body, they are likely to better represent the overall cell temperature. One of the thermocouples spot-welded to the cell body, rather than the supplied thermocouple, was used to regulate the temperature controller for the spectroscopic measurements.

To compare the actual gas temperature within the cell to the cell body temperature, three $0.25 \mathrm{~mm}$ thick type $\mathrm{K}$ thermocouples were suspended at different positions within the cell. The temperatures were monitored during a temperature ramp with pure nitrogen flowing through the cell at approximately $0.2 \mathrm{~L} / \mathrm{min}$. During a second tempcrature ramp, the $1.59 \mathrm{~mm}$ ( $1 / 16 \mathrm{in})$ stainless steel tubing used to deliver the sample gas was heated to $5{ }^{\circ} \mathrm{C}$ below the cell temperature over $0.91 \mathrm{~m}$. For each temperature reading, the system was allowed to equilibrate for approximately $1 \mathrm{~h}$.

The data in Table 4 summarize the gas temperature measurements and indicate that the three measurements are in slightly better agreement when the gas is preheated before entering the cell. Furthermore, the average gas temperature is closer to the cell body temperature with the preheating, suggesting that preheating the gas provides a more homogeneous temperature profile when the gas is flowing at $0.2 \mathrm{~L} / \mathrm{min}$. It is interesting to note that thermocouple \#l was positioned closer to the gas inlet. These measurements indicate that the gas temperature is within $0.5^{\circ} \mathrm{C}$ of the cell body temperature. The uncertainties of the gas temperature measurements are expected to be within the uncertainties of the thermocouples. At $25^{\circ} \mathrm{C}$ the uncertainty of the thermocouple is $0.5{ }^{\circ} \mathrm{C}$ while at $200{ }^{\circ} \mathrm{C}$ the uncertainty is approximately $2{ }^{\circ} \mathrm{C}$. The thermocouple calibration at $25{ }^{\circ} \mathrm{C}$ matched a NIST-calibrated thermometer to within $0.1{ }^{\circ} \mathrm{C}$. 
Spectroscopic measurements of carbon monoxide were taken at the different cell temperatures to verify the gas temperatures. A complete analysis of these data will permit a more complete verification of the cell gas temperature.

\subsection{Potential intensity artifacts}

During recent comparisons between ethylene measurements at the Pacific Northwest National Laboratory (PNNL) and NIST, we observed significant intensity artifacts. [8] In summary, two intensity artifacts are likely to be present in measurements acquired on Fourier-transform spectrometers, which have an aperture between the source and the interferometer as the main defining optical element of the system. In this design, the detector is likely to view the warm aperture as well as the source for higher resolution measurements that require a small aperture. In this case, the warm annulus of the aperture acts as a second source and distorts the line shapes and intensities in the fingerprint region of the spectrum. A second intensity artifact can arise from light exiting the interferometer back toward the source. Some of this light can be reflected off of the defining aperture and back into the interferometer and toward the detector. Since this light is double modulated by the interferometer, a $2 \mathrm{f}$ alias signal is detected.

An extensive effort was made to reduce these intensity artifacts and to demonstrate that biases between measurements can be minimized. Measurements of ethylene were found to be an excellent way to test for the intensity artifacts. The fine structure in the ethylene spectrum made it possible to see the line distortions in the fingerprint region. Ethylene band intensity measurements taken at PNNL where the intensity artifacts were minimized and NIST measurements were in good agreement. For the NIST measurements, the multi-pass cell was found to act as an optical filter to reduce stray radiation.

Since a commercial multi-pass cell was purchased for the purposes of these temperaturedependent measurements, an effort was made to assure that the intensity artifacts were minimized under the measurement conditions. During these comparisons, an additional aperture between the source and defining aperture was also added to the NIST spectrometer to reduce the heating of the defining aperture by the source. Table 5 compares the intensity ratio of the $\mathrm{CC}$ - and $\mathrm{CH}$-bands for ethylene spectra acquired with the new multi-pass cell and ethylene absorption coefficient data in NIST SRD 79. Comparing the ratios of the $\mathrm{CC}$-band to the $\mathrm{CH}$-band removes any biases due to path length and/or sample concentrations. If the aperture was acting as a second source, the lower frequency band intensity would be larger resulting in a larger $\mathrm{CC} / \mathrm{CH}$ band ratio. Data presented in Table 5 show that the band ratio of this work agrees with the NIST SRD 79 data to within $0.5 \%$.

\subsection{Sample emission effects}

In these temperature-dependent studies, emission from the sample cell as well as emission from the gas sample can impact the measurements, depending on the design of 
the FT-spectrometer.[9] The typical intcrferometer design with flat-mirror optics and the sample chamber positioned between the interferometer and the detector was used for these measurements. Fortunately, since only modulated light contributes to the interferogram in an FT spectrometer, any radiation from the sample or ccll that is dirccted towards the detector does not contribute to the spectrum. Modulated sample emission, however, can occur in interferometers with flat-mirror optics: some of the sample cmission that is directed toward the source can enter the interferometer and then is reflected back through the interferometer toward the detector.[10] For room temperature experiments, the sample emission contribution to the interferogram is minimal, since the source operates at a much higher temperature. Figure 1 shows single-beam spectra recorded with ultra-high purity nitrogen flowing through the cell and the cell temperature regulated at $25^{\circ} \mathrm{C}, 100^{\circ} \mathrm{C}$, and $200^{\circ} \mathrm{C}$ for a) the source-on and b) the source-off. It is clear that as the sample temperature is increased, the sample cell emission changes.

Ballard et al. suggested that the true gas sample transmittance spectrum can be obtained by recording spectra at two source temperatures. [10] Subtraction of the single-beam spectra at the different source temperatures, with appropriate consideration of the signal phase differences, removes signal from all radiation other than the source. The true transmittance spectrum, $T$, is given by dividing the corrected sample and corrected background single-beam spectra:

$$
T=\frac{\mathrm{S}_{1}\left(\mathrm{~T}_{1}\right)-\mathrm{S}_{1}\left(\mathrm{~T}_{2}\right)}{\mathrm{S}_{2}\left(\mathrm{~T}_{1}\right)-\mathrm{S}_{2}\left(\mathrm{~T}_{2}\right)}
$$

where $S_{1}$ and $S_{2}$ denote the sample and background single-beam spectra, respectively. $T_{1}$ and $T_{2}$ represent the source-on and source-off temperatures, respectively.

One key concern regarding this correction method was that the phase differences from the source and cell emission were correctly considered. As a check, we performed the equivalent correction in the interferogram domain by subtracting the source-off interferogram from the source-on interferogram and then generated a single beam spectrum, $S_{\text {corr }}$, by applying the Fourier-transform with the Mertz phase correction method. This corrected single-beam spectrum was then compared with the single-beam spectrum, $\mathrm{S}_{\text {uncorr }}$, prepared directly from a source-on interferogram using the Mertz phase correction. Figure 2 compares $\mathrm{S}_{\text {corr }}-\mathrm{S}_{\text {uncorr }}$ for the eight temperatures used in these measurements.

$\mathrm{S}_{\text {corr }}-\mathrm{S}_{\text {uncorr }}$ at $200{ }^{\circ} \mathrm{C}$ has the largest positive difference indicating that the correction increases the intensity of the single-beam spectrum compared to the uncorrected singlebeam spectrum. This supports the model that light from the cell emission is 180 degrees out-of-phase with the light from the source, thereby reducing the overall intensity in the measured interferogram. In this case, in the spectral domain where the Mertz phase correction removes the phase offset, the corrected single-beam spectrum is obtained by adding the single-beam spectra for the source-on and source-off. Figure $3 a$, compares results from the correction in the interferogram and spectral domains and shows that the 
two correction methods are equivalent. For this case, using the Mertz phase correction to generate the single-beam spectra, the true transmittance spectrum is given by:

$$
T=\frac{\mathrm{S}_{1}\left(\mathrm{~T}_{1}\right)+\mathrm{S}_{1}\left(\mathrm{~T}_{2}\right)}{\mathrm{S}_{2}\left(\mathrm{~T}_{1}\right)+\mathrm{S}_{2}\left(\mathrm{~T}_{2}\right)}
$$

Figure 2 shows that as the cell temperature is reduced, the difference between $\mathrm{S}_{\text {corr }}-\mathrm{S}_{\text {uncorr }}$ diminishes until about $75^{\circ} \mathrm{C}$. Below $75^{\circ} \mathrm{C}$, the correction changes sign and increases in absolute magnitude. This effect is likely due to changes in the dominant source of background modulated radiation at these cell temperatures. At $50{ }^{\circ} \mathrm{C}$ and below, background radiation from the source side, which is in phase with the source radiation, begins to dominate over the cell emission. This is confirmed by examining the singlebeam spectra with the source off at the eight temperatures shown in Figure 4 . The decrease in the intensity from $25^{\circ} \mathrm{C}$ to $75^{\circ} \mathrm{C}$, followed by the increase in intensity through $200^{\circ} \mathrm{C}$, suggests that the cell emission is not the dominant source for the modulated light until the cell reaches $100^{\circ} \mathrm{C}$.

When the ambient radiation from the source side is the primary contribution to the source-off signal, the Mertz phase correction does not introduce a phase error. In this case, the corrected single-beam spectra are obtained by subtracting the source-off spectrum from the source-on spectrum and the true transmittance is given by equation 2 . Figure $3 b$, shows that the corrections in the interferogram and spectral domains generate equivalent single-beam spectra at $25^{\circ} \mathrm{C}$.

\subsection{Data acquisition and processing}

The general procedure for data acquisition followed the protocol described previously.[3] Briefly, FT-IR spectra at $0.115 \mathrm{~cm}^{-1}$ nominal resolution were acquired using a liquid nitrogen-cooled, mercury-cadmium-telluride ( $\mathrm{HgCdTe}$ ) detector and a Bruker IFS 66V spectrometera with a $2 \mathrm{~mm}$ aperture. The optical bench was maintained under vacuum with $\mathrm{KBr}$ windows separating the optical bench from the sample compartment. Purified house air was used to purge the sample compartment and to suspend the air bearing. For these temperature-dependent studies, the sample cell was ramped to the appropriate temperature and the cell and spectrometer were allowed to equilibrate overnight before data acquisition commenced. The sample or reference gases were passed through the multi-pass gas cell at approximately $0.2 \mathrm{~L} / \mathrm{min}$. During a given day, four sample measurements were made at a specific temperature with a reference spectrum acquired at the beginning and end of the day. The temperatures and the cell pressure were monitored periodically throughout the measurements.

The large number of samples, number of temperatures, and resolution required a significant time investment to acquire the data with good signal-to-noise ratios. Several approaches were taken to improve the efficiency of the data acquisition. 1) The sourceon and source-off data were acquired on different days. 2) Source-off data were acquired for only the higher concentration samples to obtain spectra with reasonable signal-tonoise values. 3) Despite a significant effort to minimize drifts in the background, we 
observed up to $1.5 \%$ drifts in the $100 \%$ transmittance line for these measurements. The transmittance curves for each sample were corrected using a third degree polynomial fit to the arcas where there was no molecular absorption due to the sample or other gas contaminants.

The measured unapodized interferograms were transformed using the Mertz phase correction, a zero-filling factor of two, and boxcar apodization function. [11] The sourceon data were also processed with a non-linear correction routine supplied with the instrument, to account for the HgCdTe detector non-linearities.[3] No non-linear correction was used with the source-off data sincc under these conditions the single-beam spectra did not reveal any evidence of non-linear effects below the optics cut-off. Pointby-point absorption coefficients were calculated from the transmission spectra using the known concentrations and path length. Figure 5 shows a Beer's law plot for methanol and sulfur dioxide for data acquired at $25^{\circ} \mathrm{C}, 125^{\circ} \mathrm{C}$, and $200^{\circ} \mathrm{C}$. Generally, correlation coefficients $r^{2}=0.9997$ were obtained from the linear regressions, confirming the Beer's law behavior of the systems. The corrections to the absorption coefficient data to account for sample emission effects are discussed in the following sections.

\section{RESULTS}

\subsection{Methanol}

Figures $6 \mathrm{a}$ and $6 \mathrm{~b}$ show the calculated absorption coefficient data from the measured transmittance spectra for methanol at $25^{\circ} \mathrm{C}, 125^{\circ} \mathrm{C}$, and $200^{\circ} \mathrm{C}$ for the $\mathrm{CO}$ and $\mathrm{CH}_{3}$ stretch regions. Data for only three temperatures are presented for clarity. The Q-branch of methanol centered at $1033.4 \mathrm{~cm}^{-1}$ decreases by a factor of 2.68 while the peak at $2981.8 \mathrm{~cm}^{-1}$ decreases by a factor of 2.17 as the temperature is raised from $25^{\circ} \mathrm{C}$ to $200{ }^{\circ} \mathrm{C}$. The absorption features in both regions also broaden with increased temperature. The unccrtainty in the absorption coefficient data was analyzed by the procedure outlined previously.[3] The uncertainty analysis included the statistical, Type A, unccrtainties, in the measurement as well as estimates for the non-statistical, Type B, uncertainties, such as the cell path length and non-linearity of the detector. The overall uncertainty in the measurements was dominated by the $1.0 \%$ estimated relative standard uncertainty of the detector non-linearity. For the temperature-dependent methanol data, the average relative expanded uncertainty for absorption coefficient values greater than $1 \times 10^{-4}(\mu \mathrm{mol} / \mathrm{mol})^{-1} \mathrm{~m}^{-1}$ is $2.1 \%$

To account for the sample and cell emission effects at every temperature, absorption coefficient curves were also calculated from true transmittance spectra using the correction described in section 2.5. Only data for the higher concentration samples were used for the calculations, because the signal-to-noise values for the source-off measurements was low. At $25^{\circ} \mathrm{C}$, Figure $7 \mathrm{a}$, shows the uncorrected and corrected absorption coefficient spectra along with the difference spectra for both the $\mathrm{CO}$ and $\mathrm{CH}_{3}$ stretch regions. For the $\mathrm{CO}$ stretch region, there is a small difference in the spectra at $1033 \mathrm{~cm}^{-1}$. In the $\mathrm{CH}_{3}$ stretch region there is no obvious difference. The feature at $2962 \mathrm{~cm}^{-1}$ corresponds to a consistent electronic noise spike artifact that we have 
observed in our measurements. At $200{ }^{\circ} \mathrm{C}$, Figure $7 \mathrm{~b}$ shows that there is no sample emission correction in the $\mathrm{CH}_{3}$ stretch region. There is, however, a significant difference in the uncorrected and corrected absorption coefficient spectra for the CO stretch region. Comparing the integrated band intensity indicates that the emission correction decreases the overall band intensity by approximately $10 \%$.

Table 6 summarizes the emission corrections for all eight temperatures for both absorption features based on comparing integrated band intensities. It is clear from Table 6 that there is no difference for the $\mathrm{CH}_{3}$ stretch region at $3000 \mathrm{~cm}^{-1}$. For the $\mathrm{CO}$ stretch band, the magnitude of the emission correction increases from $0.4 \%$ to $9.8 \%$ as the temperature is increased from $25^{\circ} \mathrm{C}$ to $200{ }^{\circ} \mathrm{C}$. At $1000 \mathrm{~cm}^{-1}$, there is substantially more sample cell blackbody emission compared to $3000 \mathrm{~cm}^{-1}$ as demonstrated in Figure 4. As a result, the sample emission corrections become significant at $1000 \mathrm{~cm}^{-1}$ and increase as a function of cell temperature. The actual magnitude of sample emission corrections will be strongly dependent on the optics of a given measurement.

\subsection{Sulfur dioxide}

The uncorrected absorption coefficient spectra for sulfur dioxide are displayed in Figures $8 \mathrm{a}, 8 \mathrm{~b}$, and $8 \mathrm{c}$ for the symmetric stretch $\left(v_{1}\right)$, the antisymmetric stretch $\left(v_{3}\right)$ and the combination $\left(v_{1}+v_{3}\right)$ bands. The absorption features at $1136.1 \mathrm{~cm}^{-1}, 1361.0 \mathrm{~cm}^{-1}$, and $2498.5 \mathrm{~cm}^{-1}$ decrease by a factor of $2.4,2.8$, and 2.6 respectively as the temperature is increased from $25{ }^{\circ} \mathrm{C}$ to $200{ }^{\circ} \mathrm{C}$. All three bands broaden over the same temperature range. For the temperature dependent sulfur dioxide data, the average relative expanded uncertainty for absorption coefficient values greater than $1 \times 10^{-4}(\mu \mathrm{mol} / \mathrm{mol})^{-1} \mathrm{~m}^{-1}$ is $2.0 \%$.

A similar approach was followed to correct the absorption coefficient spectra for emission effects. Only the three highest concentration samples were used to obtain the source-off data. At these concentration path length products, the absorption for the $v_{3}$ band was saturated, therefore only corrected band intensities are given for the $v_{1}$ and the $v_{1}+v_{3}$ bands. Since the $v_{3}$ band overlaps with $v_{2}$ water absorption features, it is unlikely that this $\mathrm{SO}_{2}$ band would be used for quantitative gas monitoring of stack effluents.

Figures $9 \mathrm{a}$ and $9 \mathrm{~b}$ show the uncorrected and corrected absorption coefficient data for the $v_{1}$ and $v_{1}+v_{3}$ bands along with the difference spectra. At $25^{\circ} \mathrm{C}$ the uncorrected and corrected absorption coefficient spectra overlap for the $v_{1}+v_{3}$ band while there is a small difference in the spectra for the $v_{1}$ band. At $200{ }^{\circ} \mathrm{C}$, Figure $9 \mathrm{~b}$ shows that there is no emission correction for the $v_{1}+v_{3}$ band. There is, however, a significant difference in the uncorrected and corrected absorption coefficient spectra for the $v_{1}$ band. Comparing the integrated band intensity indicates that the cmission correction decreases the overall $v_{1}$ band intensity by approximately $10 \%$.

Table 7 summarizes the sample emission corrections for all eight temperatures for the $v_{1}$ and $v_{1}+v_{3}$ bands by comparing integrated band intensities. Table 7 shows that the 
magnitude of the emission correction for the $v_{1}$ band increases from $0.9 \%$ to $9.9 \%$ as the temperature is increased. The differences in the integrated band intensities for the $v_{1}+v_{3}$ band range from $0.6 \%$ to $-0.6 \%$ over the temperature range.

\section{DISCUSSION}

The results show that for methanol and sulfur dioxide, the peak intensities, band shapes, and integrated band intensities change substantially with temperature. Changes in the peak intensities and band shapes are due to the temperature dependence of the Boltzmann rotational and vibrational population distributions. A large fraction of the integrated band intensity changes can be attributed to the sample number density changes with temperature. Table 8 lists the calculated changes in the number density, using the ideal gas law, compared to $25^{\circ} \mathrm{C}$ and the relative changes in the corrected integrated band intensities for methanol and sulfur dioxide. For both sulfur dioxide bands, the changes in the band intensities track the changes in the sample number density. For methanol, the integrated band intensities decrease more rapidly with temperature than the sample number density. Since methanol has low-lying torsional modes, the spectroscopic properties of methanol will be more sensitive to temperature changes compared to sulfur dioxide. The decomposition of methanol may also contribute to the decreased band intensities observed at $200{ }^{\circ} \mathrm{C}$. At this temperature, carbon dioxide features appeared in the methanol spectra. Performing these measurements with a nitrogen matrix rather an air matrix might decrease the methanol decomposition at elevated temperatures.

The results of this work also confirm that emission from the sample and sample cell can impact the absorption coefficient measurements. Tables 6 and 7 show that the emission correction is strongly dependent on the wavelength. Since the optical bench components and design also impact the emission effects, it is necessary to characterize this correction for each system. Alternatively, a corner cube or cat's eye interferometer, which spatially offsets sample emission and source radiation, can be used to eliminate the emission effects. We hope to validate the current correction method by performing similar absorption coefficient measurements with a corner cubc or cat's eye interferometer.

\section{CONCLUSIONS}

The infrared absorptivity assessments for methanol and sulfur dioxide are made for temperatures ranging from $25^{\circ} \mathrm{C}$ to $200{ }^{\circ} \mathrm{C}$ at $25^{\circ} \mathrm{C}$ increments using an FT spectrometer with NIST primary gas mixture standards and a well-charactcrized system. Experimental parameters that could lead to systematic errors were carefully cxamined. In order to correct for the sample and sample cell emission effects, sample and reference data are acquired with the infrared source on and source off. The true transmittance of each measurement is calculated following the method proposed by Ballard et al.[10] This correction in the spectral domain is verified by comparing the results to a correction in the interferogram domain. Absorption coefficients are computed from uncorrected and corrected transmittance spectra for each target gas temperature. Excluding the sample emission bias, the average relative expanded uncertainty for the methanol and sulfur dioxide uncorrected absorption coefficicnts is found to be $2.1 \%$ and $2.0 \%$ for absorptivity values greater than $1 \times 10^{-4}(\mu \mathrm{mol} / \mathrm{mol})^{-1} \mathrm{~m}^{-1}$. The average relative expanded 
uncertainty is $2.5 \%$ for the absorption coefficient data corrected for sample emission effects.

The emission correction tracks the blackbody emission of the sample cell and is both wavelength- and temperature-dependent. For temperatures up to $200{ }^{\circ} \mathrm{C}$, there is no emission correction for bands at $2600 \mathrm{~cm}^{-1}$ and higher. In the fingerprint region, the emission correction becomes significant especially at temperatures above $100{ }^{\circ} \mathrm{C}$, where the emission correction is larger than the expanded uncertainty of the uncorrected data. At $200{ }^{\circ} \mathrm{C}$, the correction was approximately $10 \%$ for bands in the spectral region of $1000 \mathrm{~cm}^{-1}$. Possible changes in the actual line shape due to the emission effects have not been evaluated. The magnitude of the emission correction will depend on the design of the optical bench; therefore it is critical to characterize the correction for each apparatus.

As expected, the peak intensities, band shapes, and integrated band intensities change with temperature. For sulfur dioxide, the change in the integrated band intensities followed the temperature changes in the sample number density. The temperaturedependence for methanol is more complex. Since the features of the absorption coefficient spectra change substantially with temperature, high-quality temperaturedependent absorption coefficient data are critical for quantitative evaluation of stack gas emissions using passive FT-IR methods, especially for more complex systems such as methanol. Temperature dependent data are even more crucial if only a small portion of the band is used for the data analysis.

\section{ACKNOWLEDGMENTS}

P.M. Chu thanks Roger Combs of Edgewood Chemical Biological Center; Walter Lafferty and John Travis of NIST; Bruce Olson a NIST retiree; and Steven Sharpe, Robert Sams, and Timothy Johnson, of Pacific Northwest National Laboratories for many helpful discussions. Additionally, the authors wish to thank Tony Schmitz for the radius of curvature measurements by interferometry.

This work was funded by the Dept. of the Army, US Army Edgewood Chemical and Biological Center, MIPR No. MIPROEDERLA309. Also partial support from NIST Technology Services is greatly appreciated.

\section{REFERENCES}

1. See for example, Beer, R., Remote Sensing by Fourier Transform Spectrometry, John Wiley \& Sons, Inc., New York, NY, 1992 and Chaffin, C.T., Marshall, T.L., and Chaffin, N.C., Field Analytical Chemistry Technology, 3, 11 (1999).

2. Chu, P.M., Guenther, F.R., Rhoderick, G.C., Lafferty, W.J., Standard Reference Database 79, version 1.0, Quantitative Infrared Database, NIST, Gaithersburg, MD (1998). 
3. Chu, P.M., Guenther, F.R., Rhoderick, G.C., Lafferty, W.J., J. Res. Natl. Inst. Stand. Technol. 104, 59 (1999).

4. Selberg, L.A., Opt Eng, 31, 1961(1992).

5. Schmitz, T., Evans, C., Davies, A., Proceedings of American Society for Precision Engineering, Tucson, AZ, May 2000.

6. EURACHEM/CITAC Guide, Quantifying Uncertainty in Analytical Measurement. Laboratory of the Government Chemist, London (2000).

7. Moore, J.H., Davis, C.C., Coplan, M.A., Building Scientific Apparatus, $2^{\text {nd }}$ Ed., Addison-Wesley Publishing Company, lnc., New York (1989).

8. Sharpe, S.W., Sams, R.L., Johnson, T.J., Chu, P.M., Fourier Transform Spectroscopy, Trends in Optics and Photonics Series, Vol 51., Optical Society of America (2001).

9. Tanner, D.B., and McCall, R.P., Applied Optics, 23, 2363 (1984).

10. Ballard, J., Remedios, J.J., Roscoe, H.K., J. Quant. Spectrosc. Radiat. Transfer, 48, 733 (1992).

11. OPUS 2.2, Bruker Instruments, Billerica, MA 01821. 
Table 1. Target experimental parameters

\begin{tabular}{|c|c|}
\hline \multicolumn{2}{|l|}{ Experimentall Parameter } \\
\hline Nominal resolution & $0.125 \mathrm{~cm}^{-1}$ \\
\hline Balance gas & $\begin{array}{l}\text { Preferably blended air } \\
\text { (Nitrogen and Oxygen) }\end{array}$ \\
\hline Temperature range & $\begin{array}{l}25^{\circ} \mathrm{C} \text { to } 200^{\circ} \mathrm{C} \text { at } 25^{\circ} \mathrm{C} \\
\text { increments }\end{array}$ \\
\hline Concentration path length range & $20 \mu \mathrm{mol}-\mathrm{m}$ to $2500 \mu \mathrm{mol}-\mathrm{m}$ \\
\hline Accuracy of gas standard & Better than $0.5 \%$ \\
\hline $\begin{array}{l}\text { Number of concentration pathlength } \\
\text { combination }\end{array}$ & 8 \\
\hline
\end{tabular}

Table 2. Gravimetrically prepared methanol-in-air and sulfur dioxide-in-nitrogen standard concentrations with the expanded uncertainties.

\begin{tabular}{cc}
$\begin{array}{c}\text { Methanol } \\
\text { Standards } \\
(\mu \mathrm{mol} / \mathrm{mol})\end{array}$ & $\begin{array}{c}\text { Sulfur dioxide } \\
\text { Stand ards } \\
(\boldsymbol{\mu m o l} / \mathrm{mol})\end{array}$ \\
\hline $10.73 \pm 0.03$ & $48.9 \pm 0.2$ \\
$38.08 \pm 0.09$ & $96.2 \pm 0.4$ \\
$50.89 \pm 0.07$ & $493 \pm 2$ \\
$75.89 \pm 0.1$ & $968 \pm 4$ \\
$102.0 \pm 0.1$ & $1475 \pm 7$ \\
$179.5 \pm 0.4$ & $2516 \pm 11$ \\
$296.7 \pm 0.4$ & $3186 \pm 14$ \\
$415.6 \pm 0.5$ & \\
\hline
\end{tabular}

Table 3. Cell path length as a function of the cell temperature, given the coefficient for thermal expansion equals $23 \times 10^{-6}{ }^{\circ} \mathrm{C}^{-1}$.

\begin{tabular}{cccc}
\hline Temperature & $\begin{array}{c}\text { Base path } \\
\text { length } \\
(\mathbf{c m})\end{array}$ & $\begin{array}{c}\text { Window to } \\
\text { mirror path } \\
\text { length }(\mathbf{c m})\end{array}$ & $\begin{array}{c}\text { Total path } \\
\text { length } \\
(\mathbf{m})\end{array}$ \\
\hline 25 & 9.9890 & 0.6805 & 2.0114 \\
50 & 9.9947 & 0.6809 & 2.0126 \\
75 & 10.0005 & 0.6813 & 2.0137 \\
100 & 10.0062 & 0.6817 & 2.0149 \\
125 & 10.0120 & 0.6821 & 2.0160 \\
150 & 10.0177 & 0.6825 & 2.0172 \\
175 & 10.0235 & 0.6828 & 2.0183 \\
200 & 10.0292 & 0.6832 & 2.0195 \\
\hline
\end{tabular}




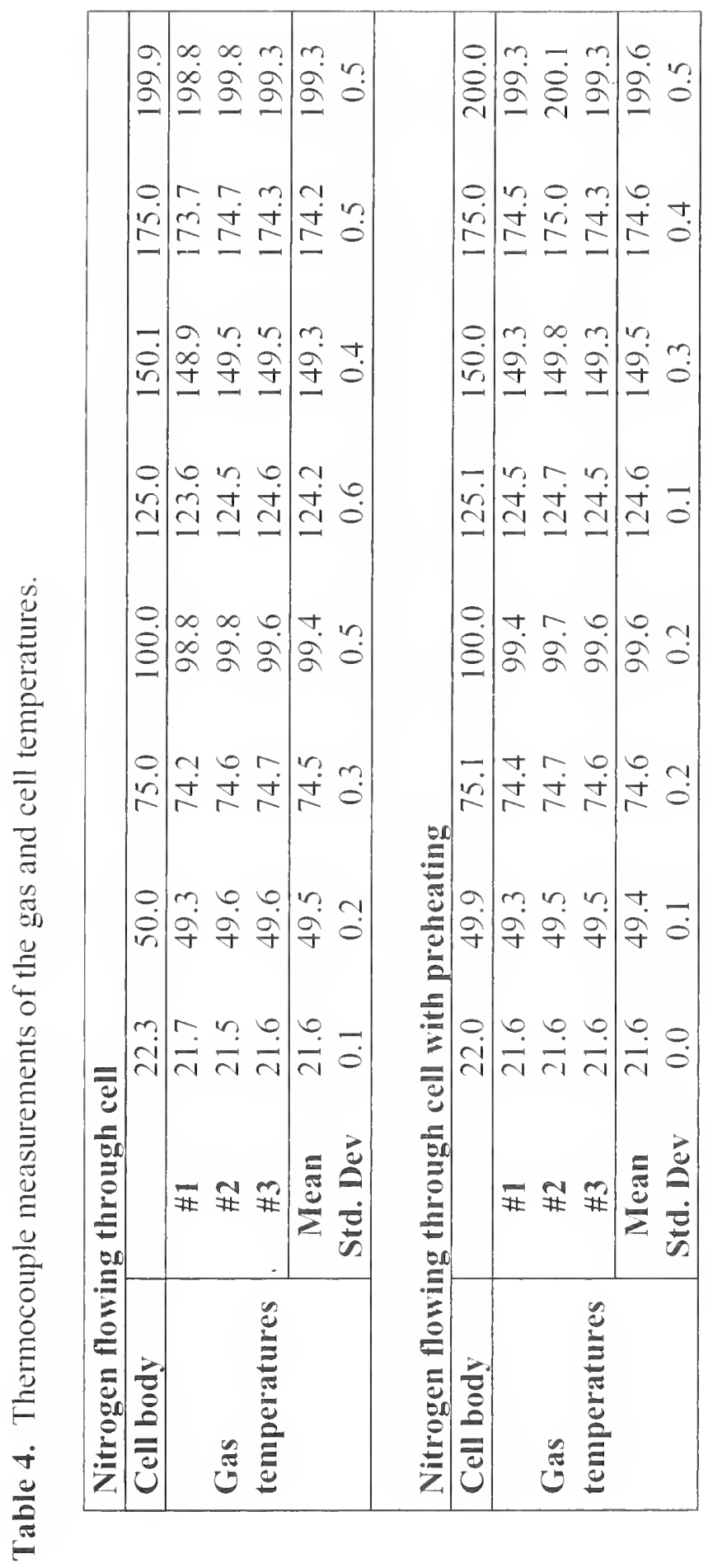




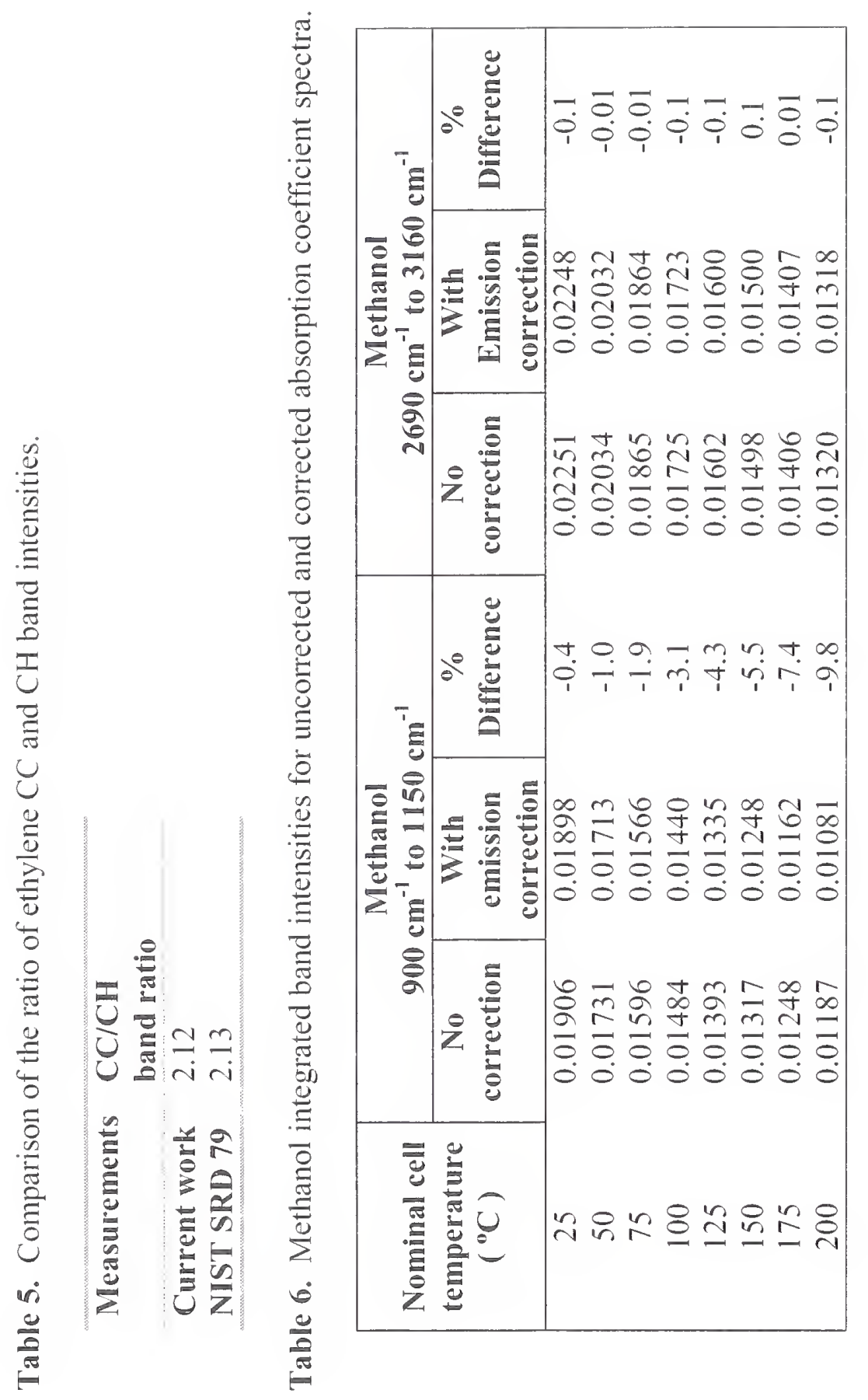




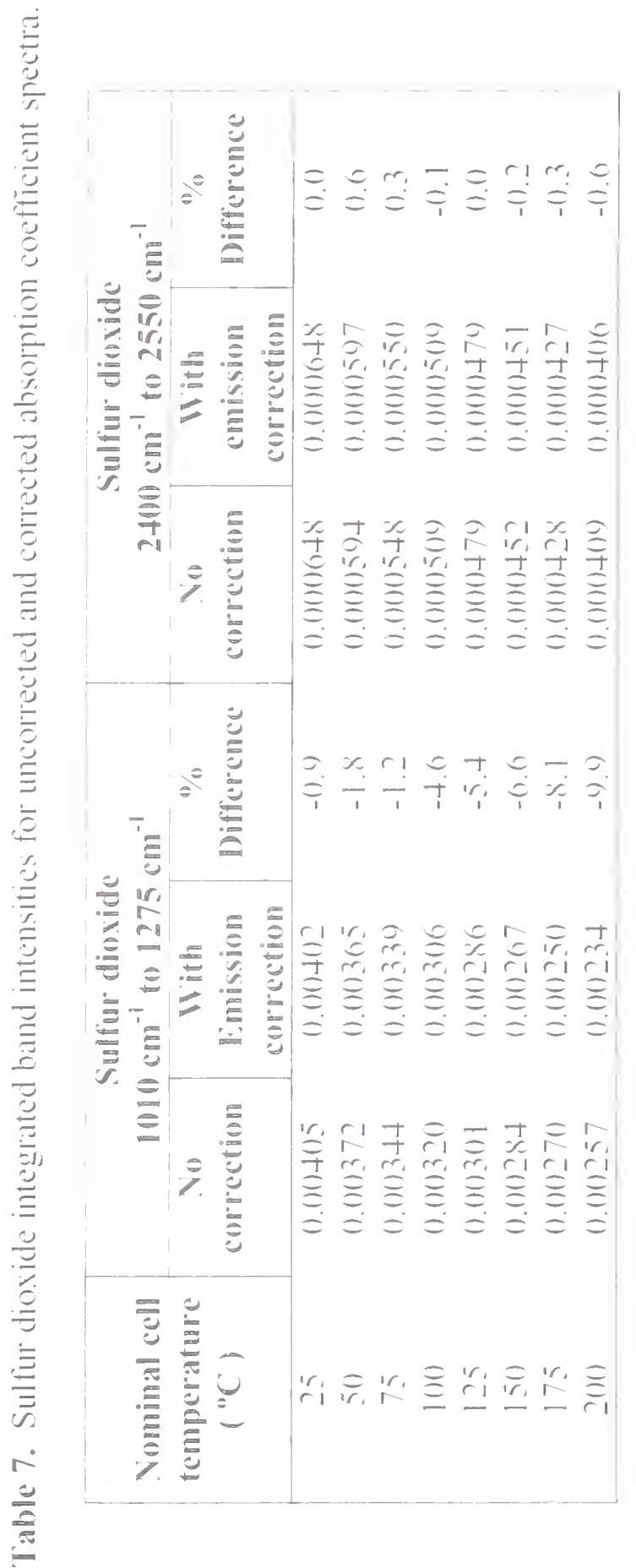


Table 8. Comparison of changes in the sample number density with relative changes in the corrected integrated band intensities for methanol and sulfur dioxide.

\begin{tabular}{|c|c|c|c|c|c|}
\hline \multirow{2}{*}{$\begin{array}{c}\text { Cell } \\
\text { temperature } \\
\left({ }^{\circ} \mathrm{C}\right)\end{array}$} & \multirow{2}{*}{$\begin{array}{c}\text { Change in } \\
\text { sample number } \\
\text { density }\end{array}$} & \multicolumn{2}{|c|}{ Methanol } & \multicolumn{2}{|c|}{ Sulfur dioxide } \\
\hline & & CO stretch & $\mathrm{CH}_{3}$ strefch & $v_{1}$ & $v_{1}+v_{3}$ \\
\hline 25 & 1.000 & 1.000 & 1.000 & 1.000 & 1.000 \\
\hline 50 & 0.923 & 0.903 & 0.904 & 0.919 & 0.917 \\
\hline 75 & 0.856 & 0.825 & 0.829 & 0.849 & 0.846 \\
\hline 100 & 0.799 & 0.759 & 0.766 & 0.790 & 0.785 \\
\hline 125 & 0.749 & 0.703 & 0.712 & 0.743 & 0.739 \\
\hline 150 & 0.704 & 0.658 & 0.667 & 0.701 & 0.698 \\
\hline 175 & 0.665 & 0.612 & 0.626 & 0.667 & 0.660 \\
\hline 200 & 0.630 & 0.570 & 0.586 & 0.635 & 0.631 \\
\hline
\end{tabular}




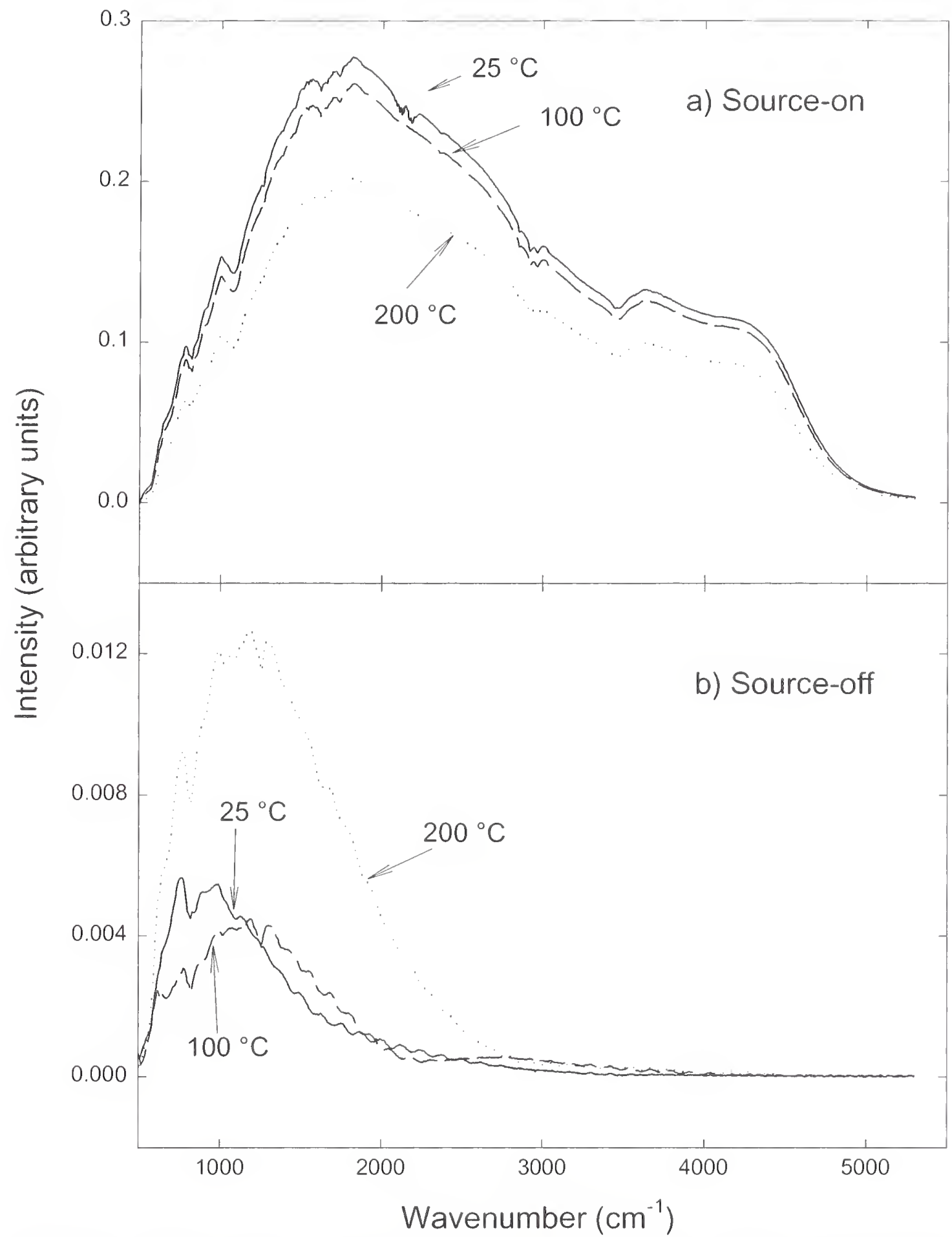

Figure 1. Single-beam spectra recorded with ultra-high purity nitrogen flowing through the cell and the cell temperature regulated at $25{ }^{\circ} \mathrm{C}(-), 100{ }^{\circ} \mathrm{C}(--)$, and $200{ }^{\circ} \mathrm{C}(\cdots)$ for a) the source-on and b) the source-off. 


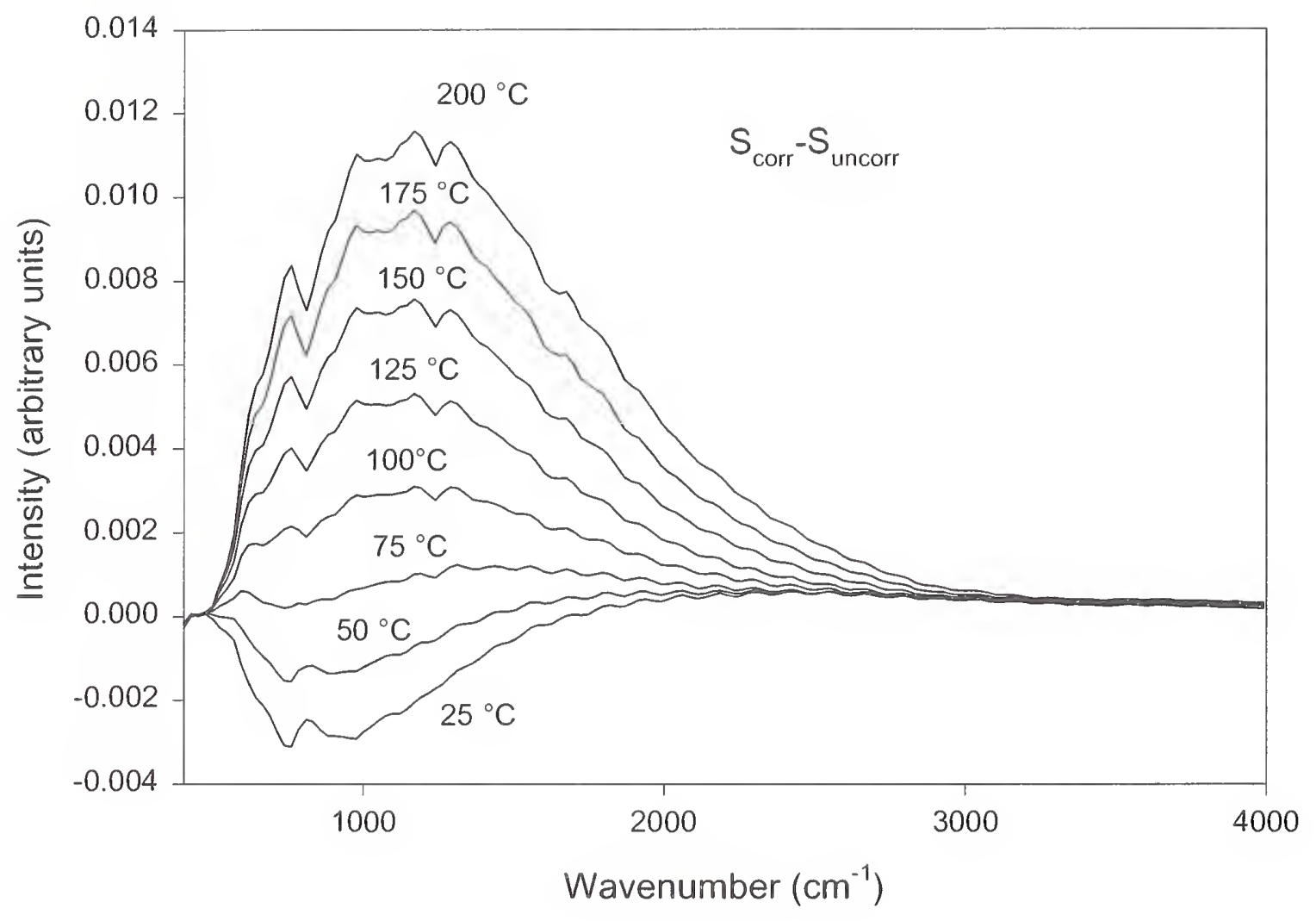

Figure 2. Scorr- Suncorr for the eight temperatures used in these measurements. 


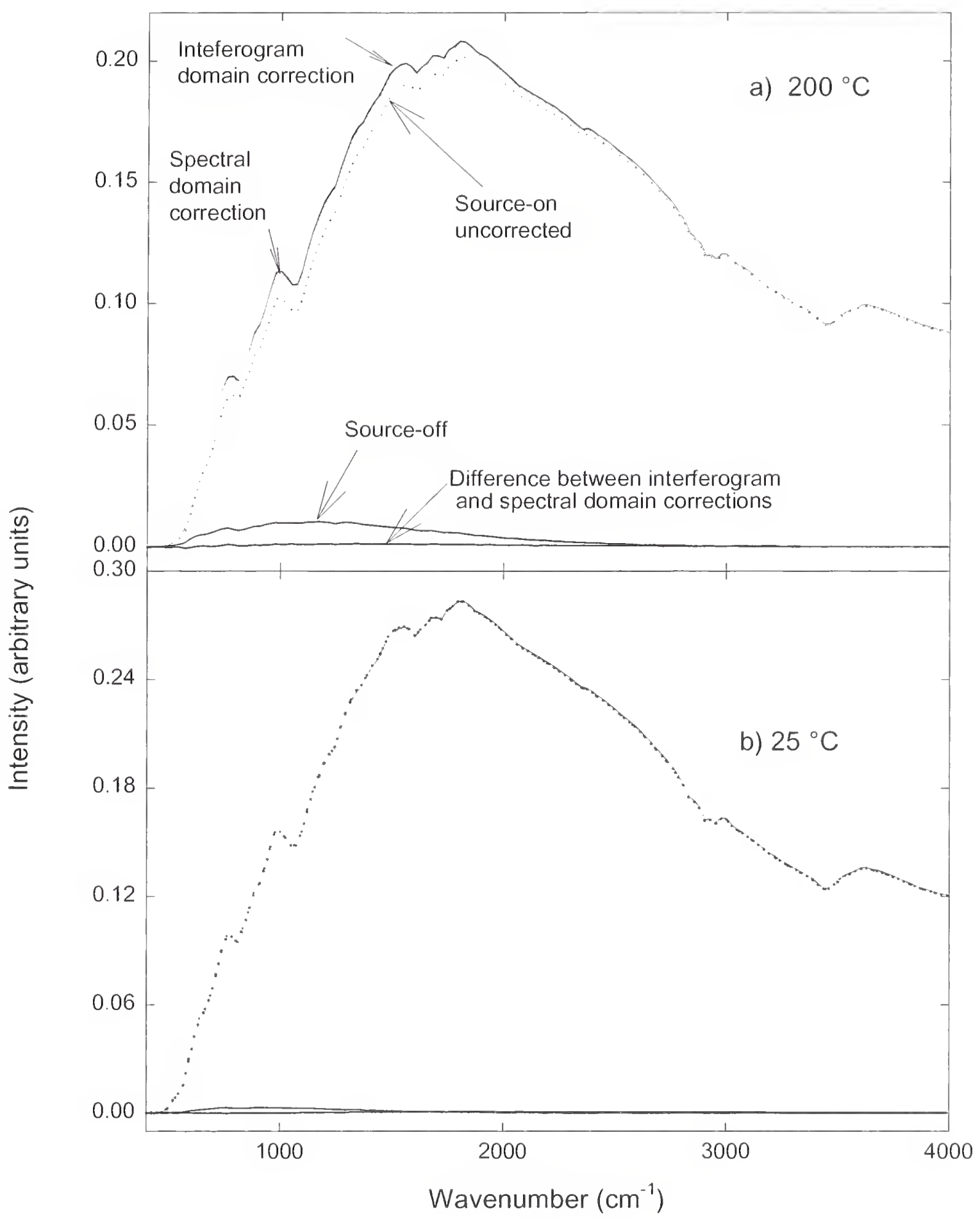

Figure 3. Results from the correction in the interferogram (-) and spectral ( ) domains along with the source-on uncorrected data ( $\cdots)$. 


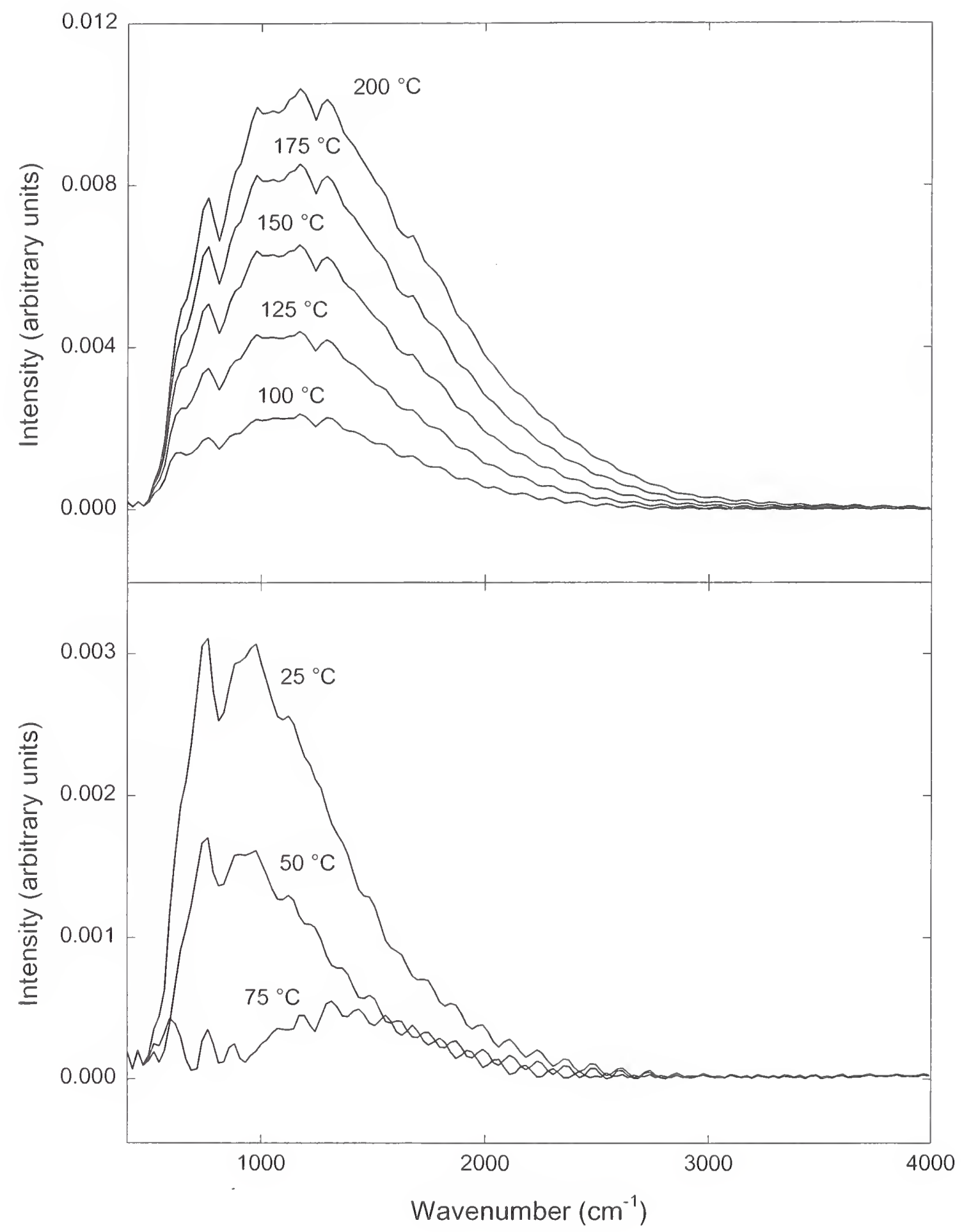

Figure 4. Single-beam spectra with ultra-high purity nitrogen flowing through the cell and the source off. 


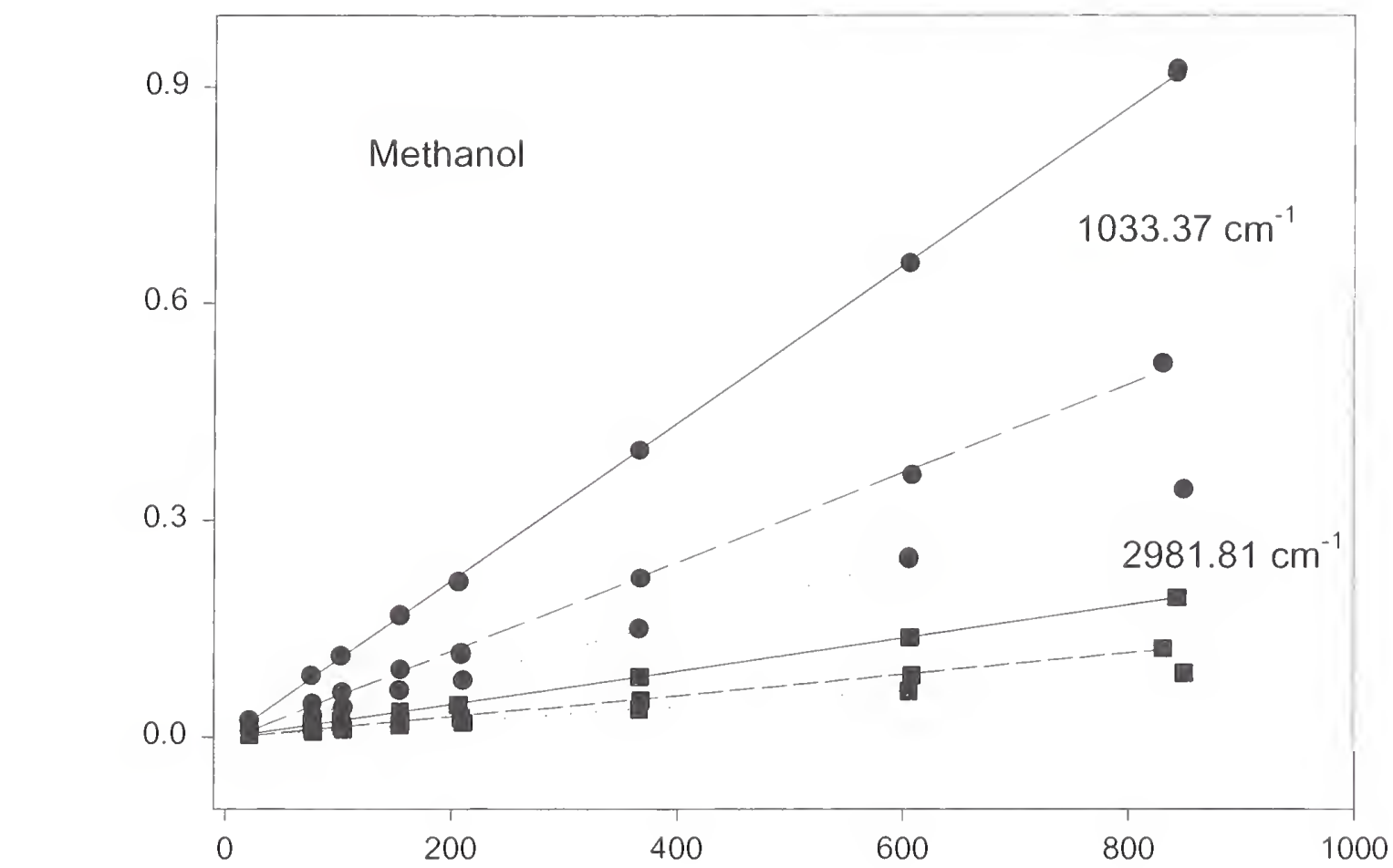

0
0
$\frac{0}{10}$
은
0
0
0
$\frac{0}{2}$

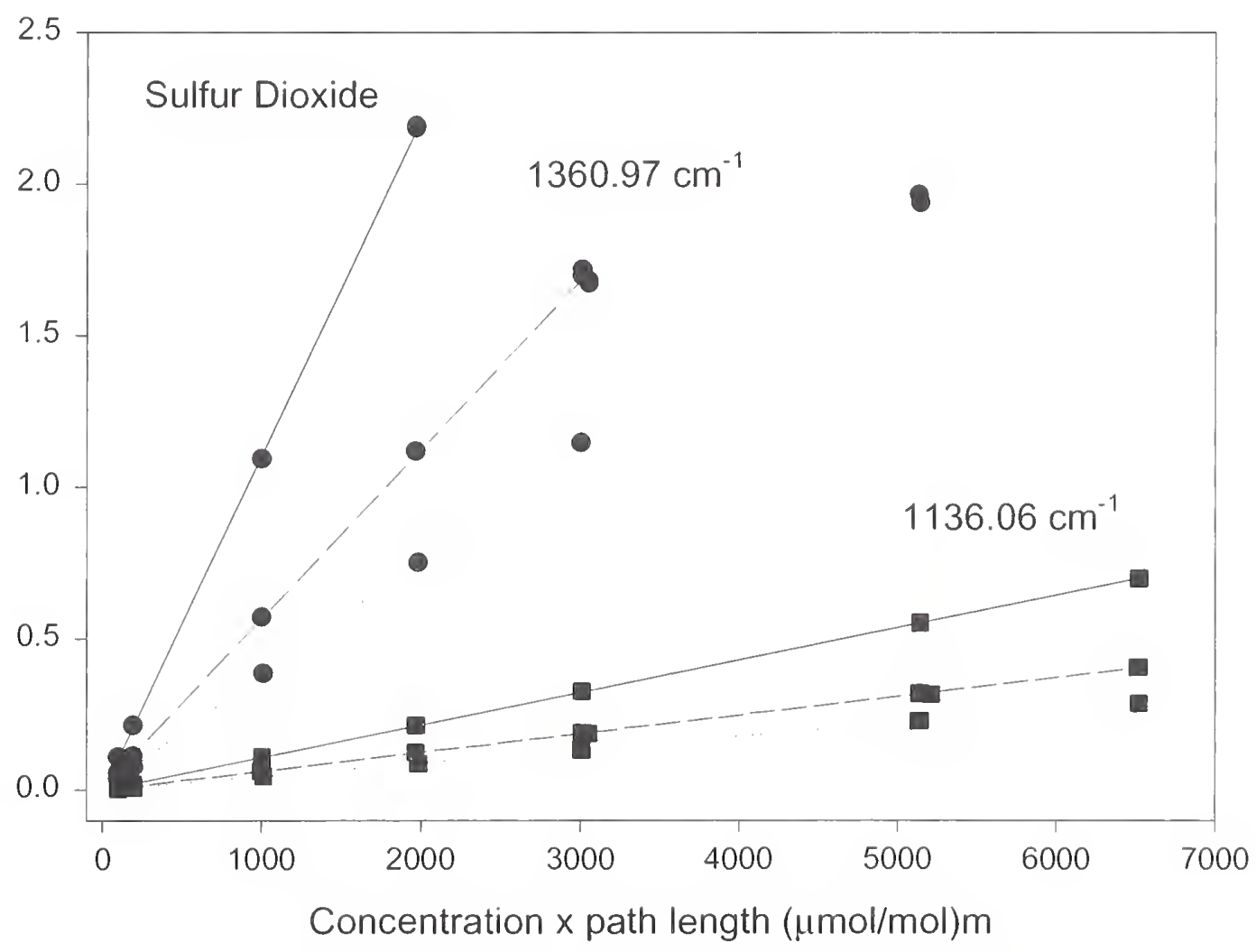

Figure 5. Beer's law plots for methanol and sulfur dioxide for data acquired at $25^{\circ} \mathrm{C}$ (-), $125^{\circ} \mathrm{C}(--)$, and $200^{\circ} \mathrm{C}(\cdots)$. 


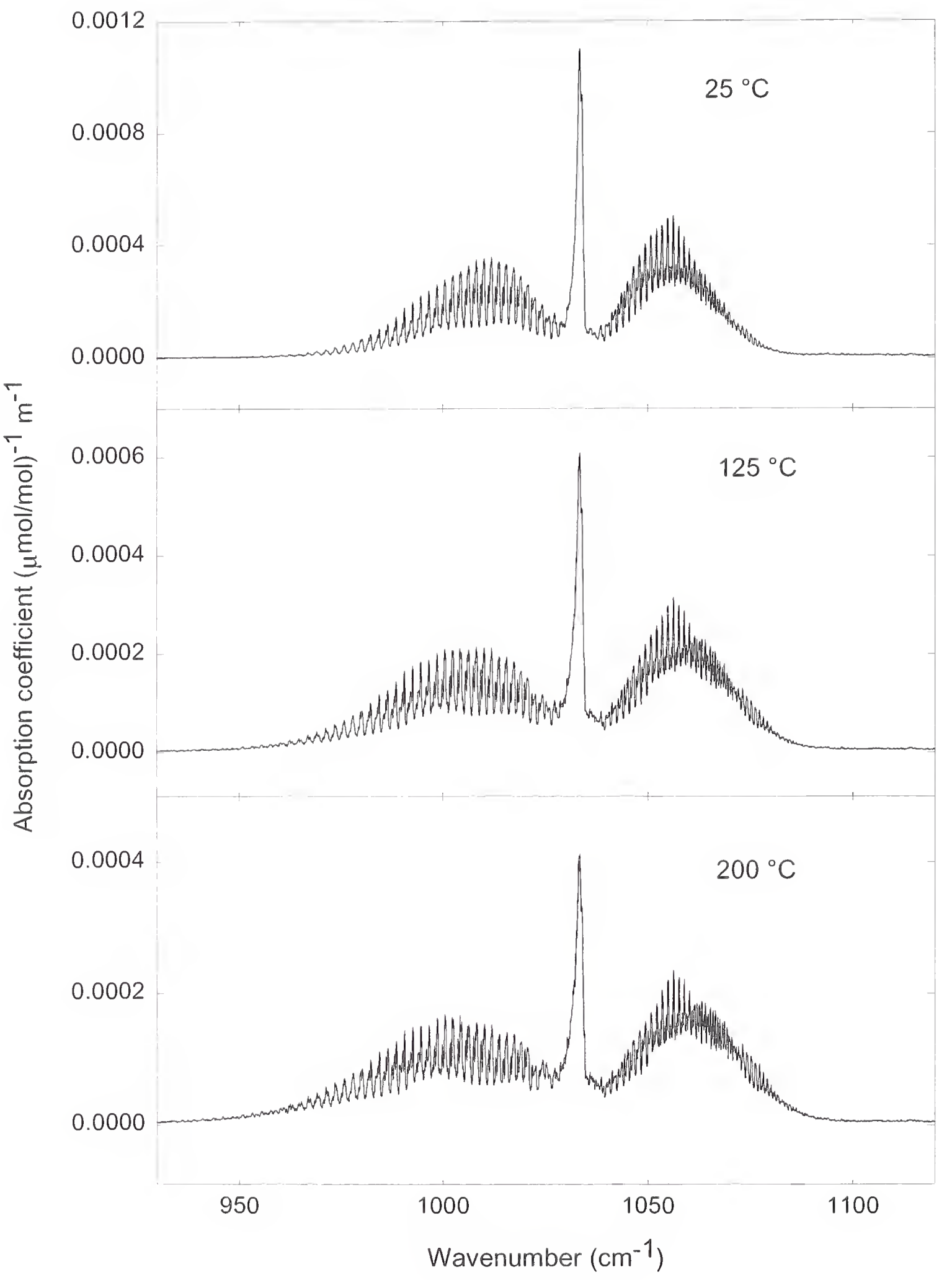

Figure 6a. Absorption coefficient data calculated from the measured transmittance spectra for methanol at $25^{\circ} \mathrm{C}, 125^{\circ} \mathrm{C}$, and $200^{\circ} \mathrm{C}$ for the $\mathrm{CO}$ stretch region. 


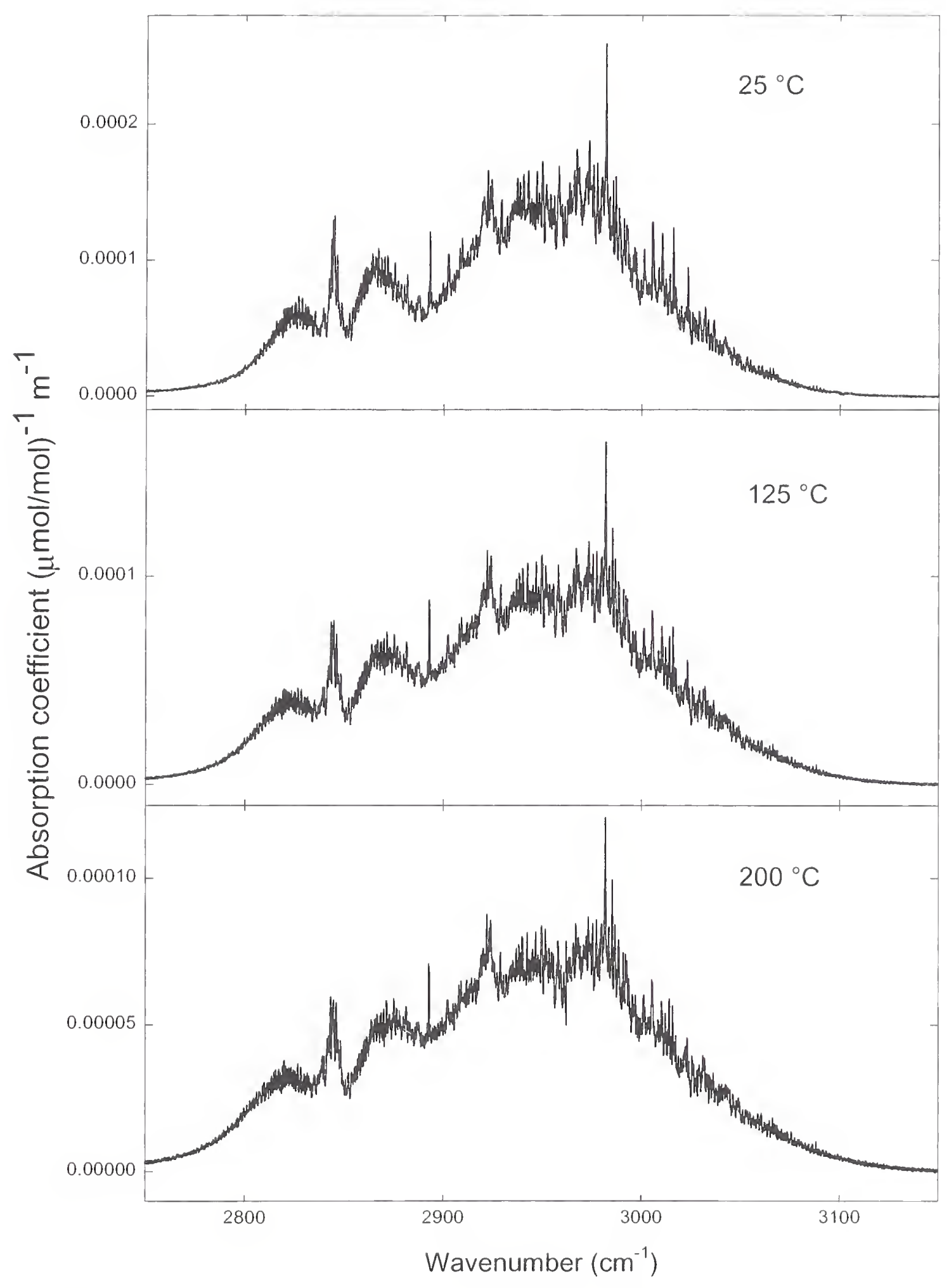

Figure 6b. Absorption coefficient data calculated from the measured transmittance spectra for methanol at $25{ }^{\circ} \mathrm{C}, 125^{\circ} \mathrm{C}$, and $200{ }^{\circ} \mathrm{C}$ for the $\mathrm{CH}_{3}$ stretch region. 


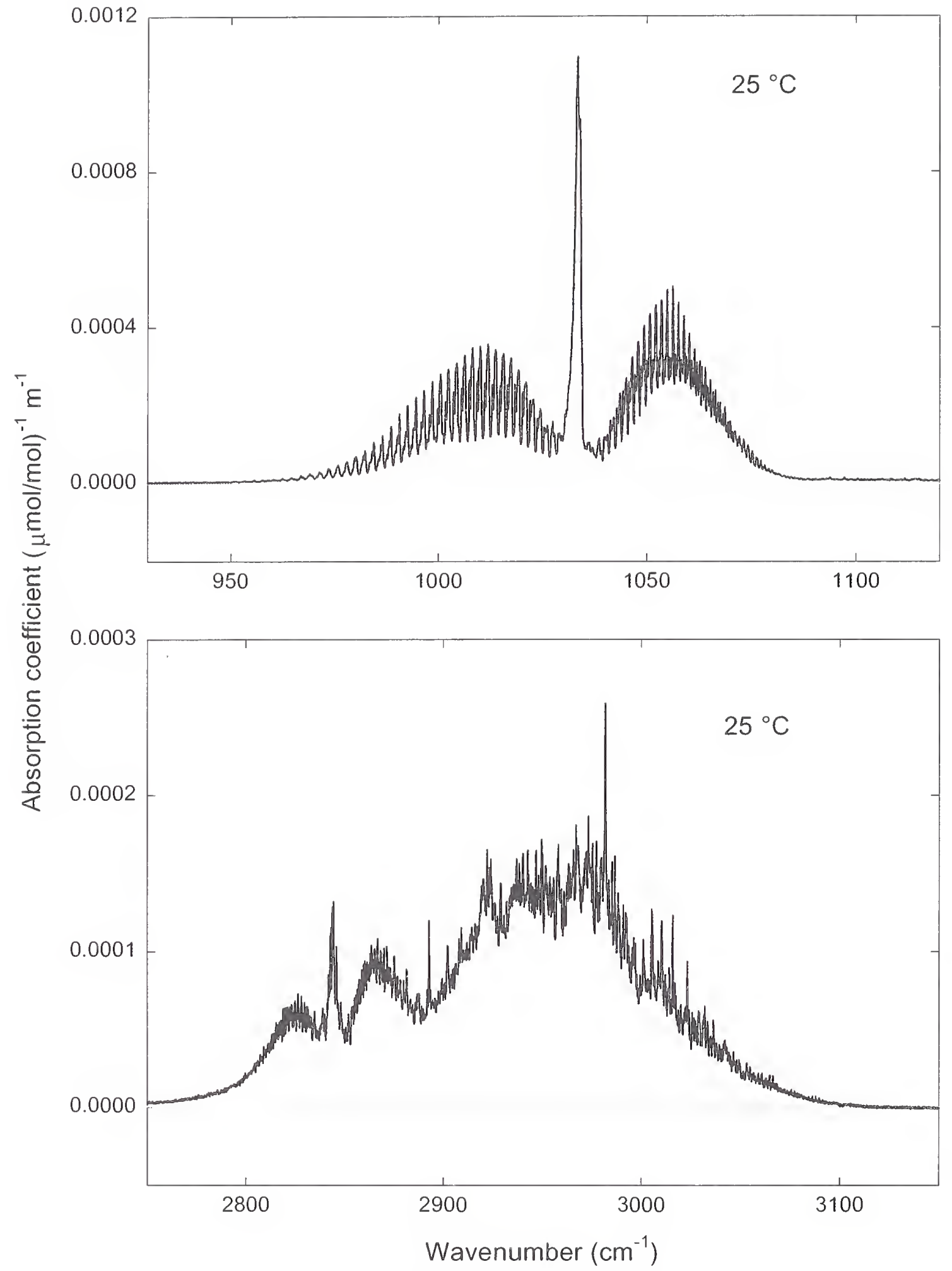

Figure 7a. An overlay of the methanol uncorrected ( $\cdots$ ) and corrected (- ) absorption coefficient spectra along with the difference spectra ( ) for both the $\mathrm{CO}$ and $\mathrm{CH}_{3}$ stretch regions, at $25^{\circ} \mathrm{C}$. 


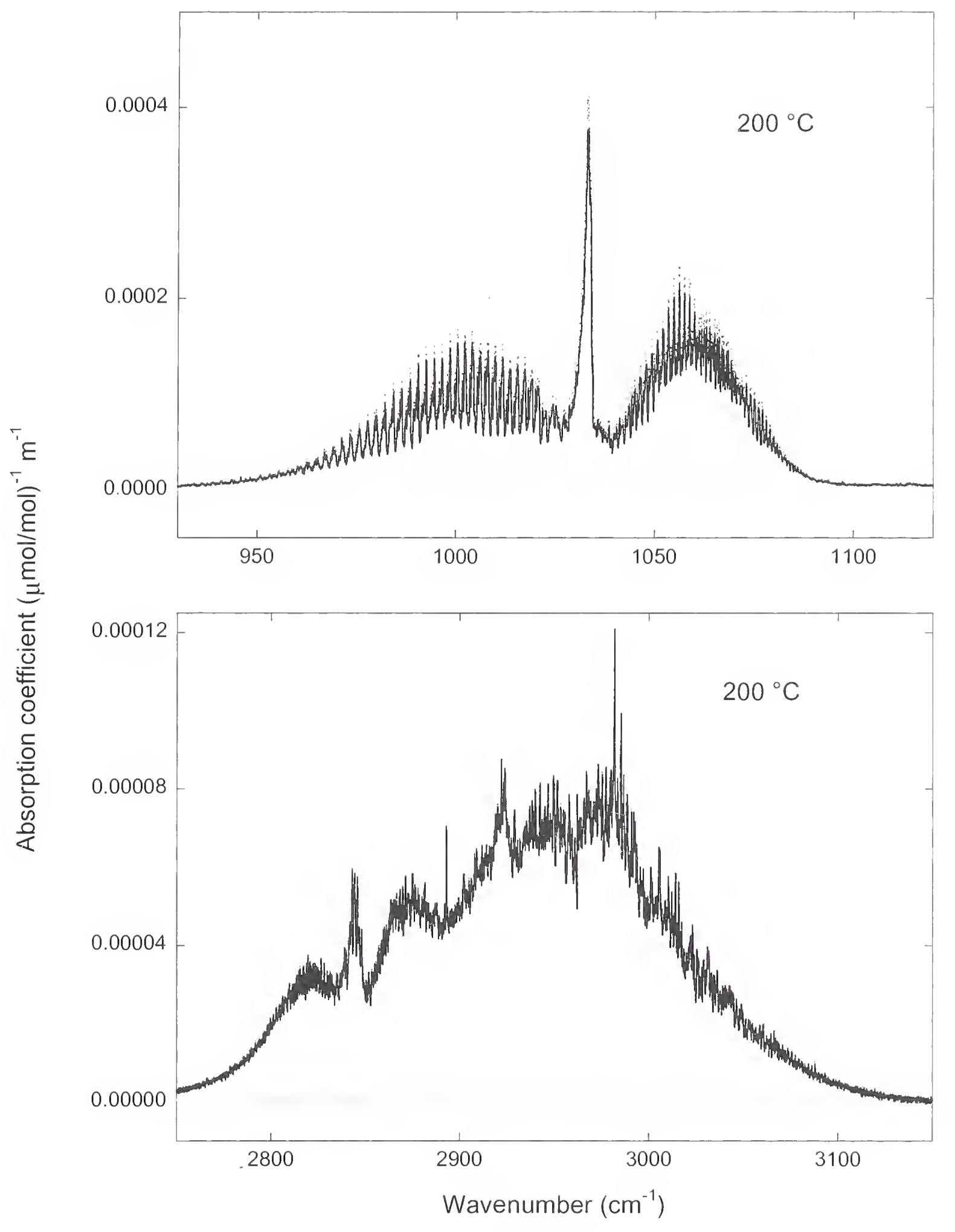

Figure $\mathbf{7 b}$. An overlay of the methanol uncorrected $(\cdots)$ and corrected (-) absorption coefficient spectra along with the difference spectra ( ) for both the $\mathrm{CO}$ and $\mathrm{CH}_{3}$ stretch regions, at $200{ }^{\circ} \mathrm{C}$. 


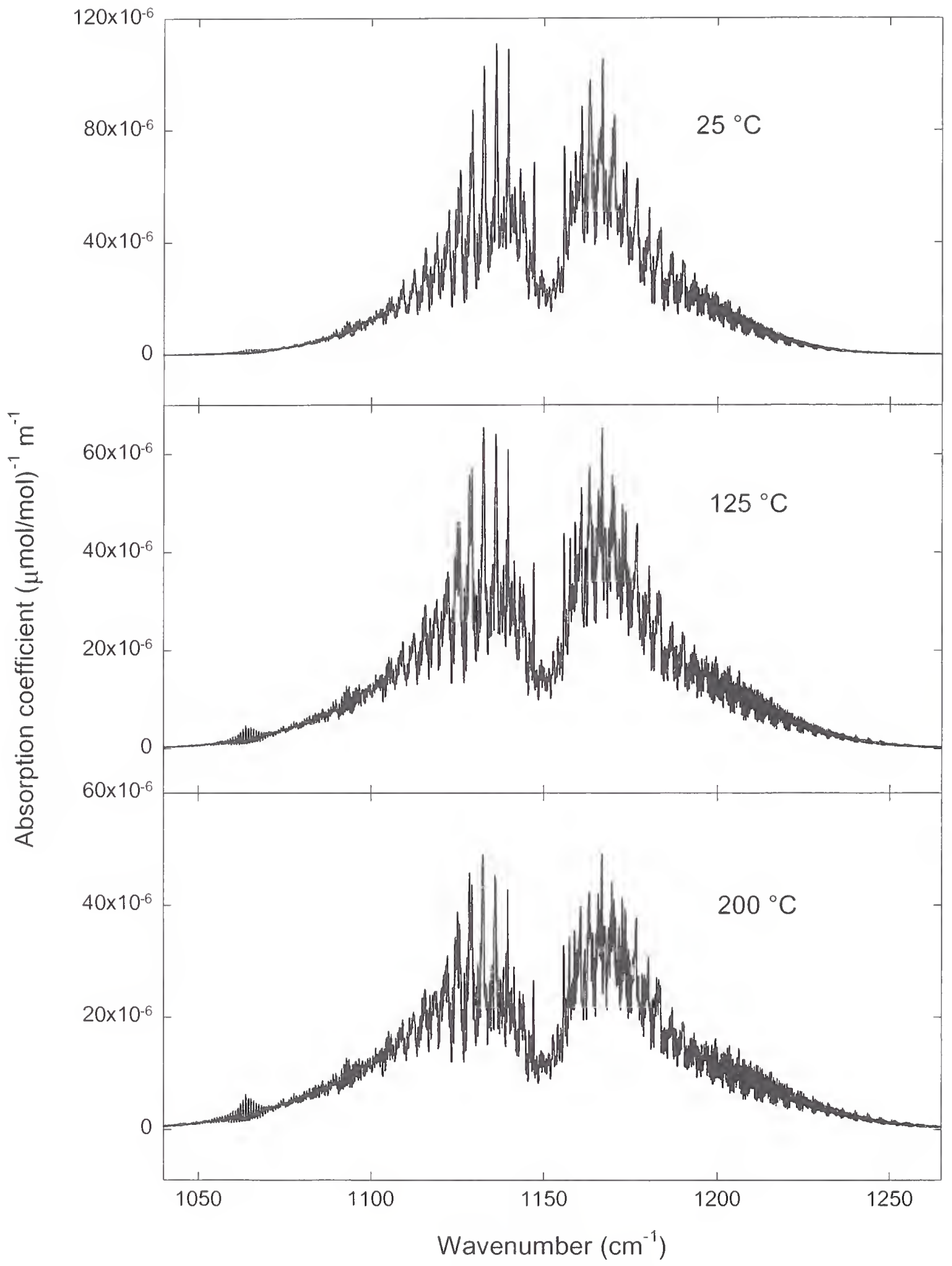

Figure 8a. Absorption coefficient data calculated from the measured transmittance spectra for sulfur dioxide at $25^{\circ} \mathrm{C}, 125^{\circ} \mathrm{C}$, and $200^{\circ} \mathrm{C}$ for the $v_{1}$ band. 


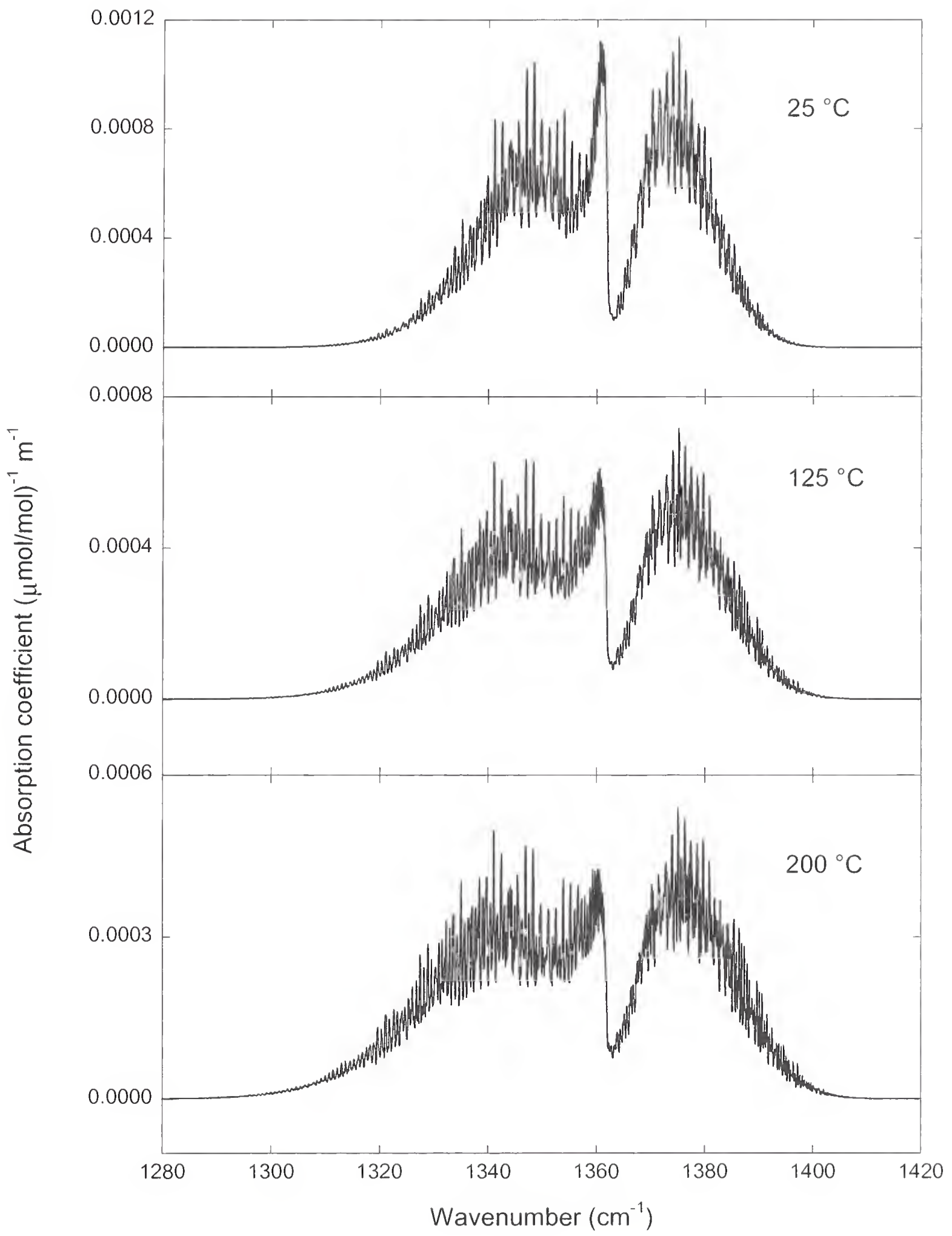

$v_{3}$ band. 


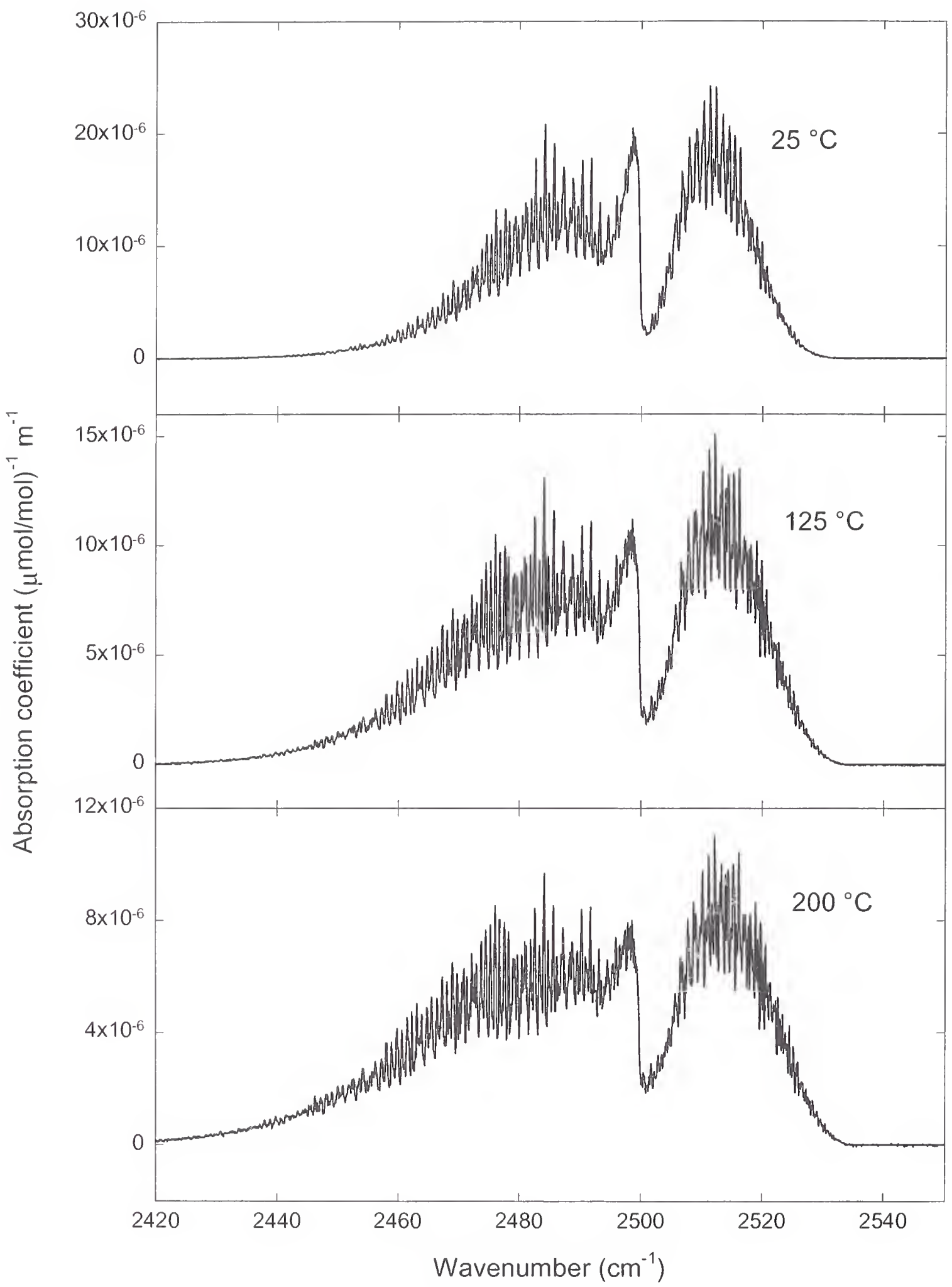

Figure 8c. Absorption coefficient data calculated from the measured transmittance spectra for sulfur dioxide at $25^{\circ} \mathrm{C}, 125^{\circ} \mathrm{C}$, and $200{ }^{\circ} \mathrm{C}$ for the $v_{1}+v_{3}$ band. 


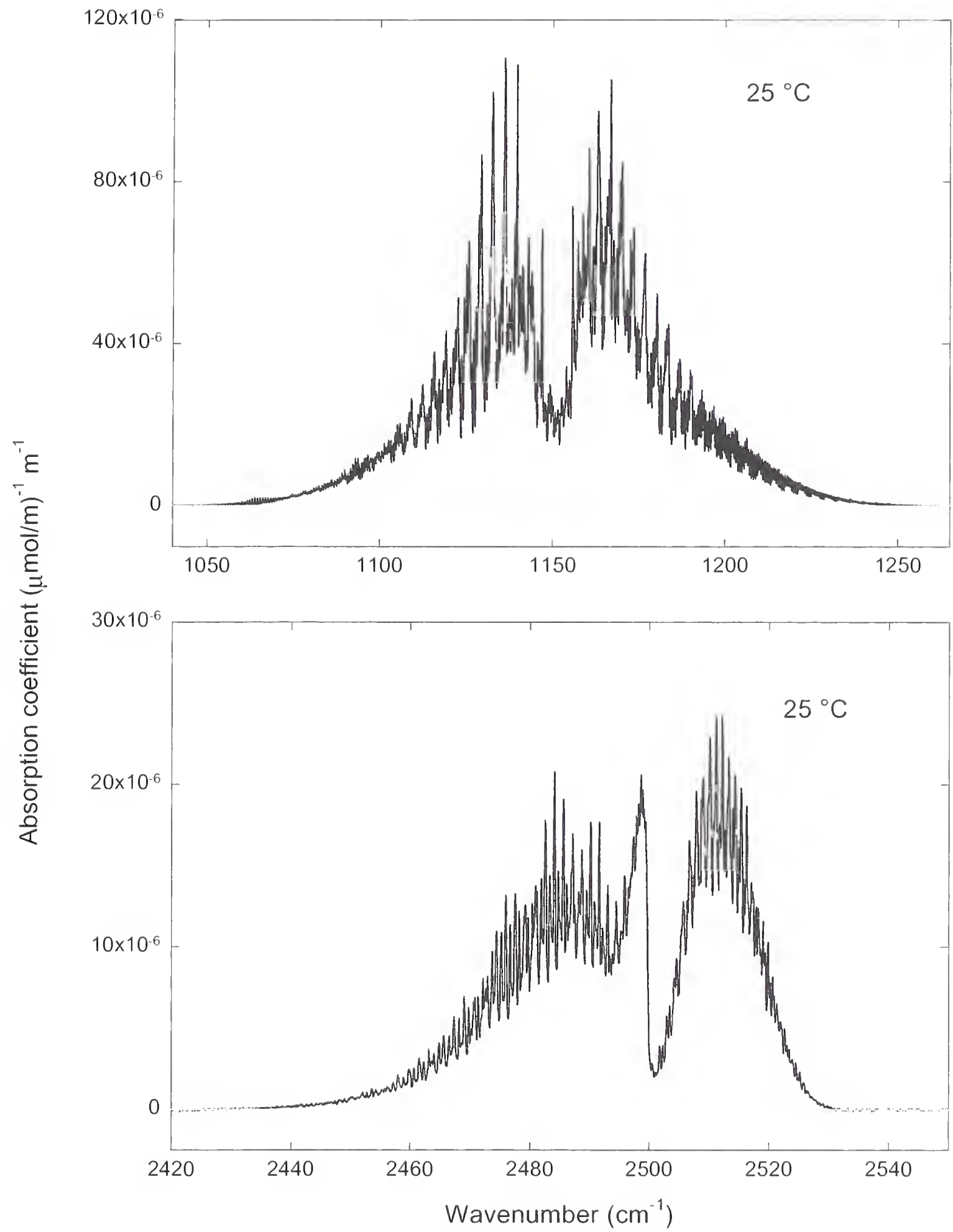

Figure 9a. An overlay of the sulfur dioxide uncorrected $(\cdots)$ and corrected (-) absorption coefficient spectra along with the difference spectra ( ) for the $v_{1}$ and $v_{1}+v_{3}$ bands, at $25^{\circ} \mathrm{C}$. 


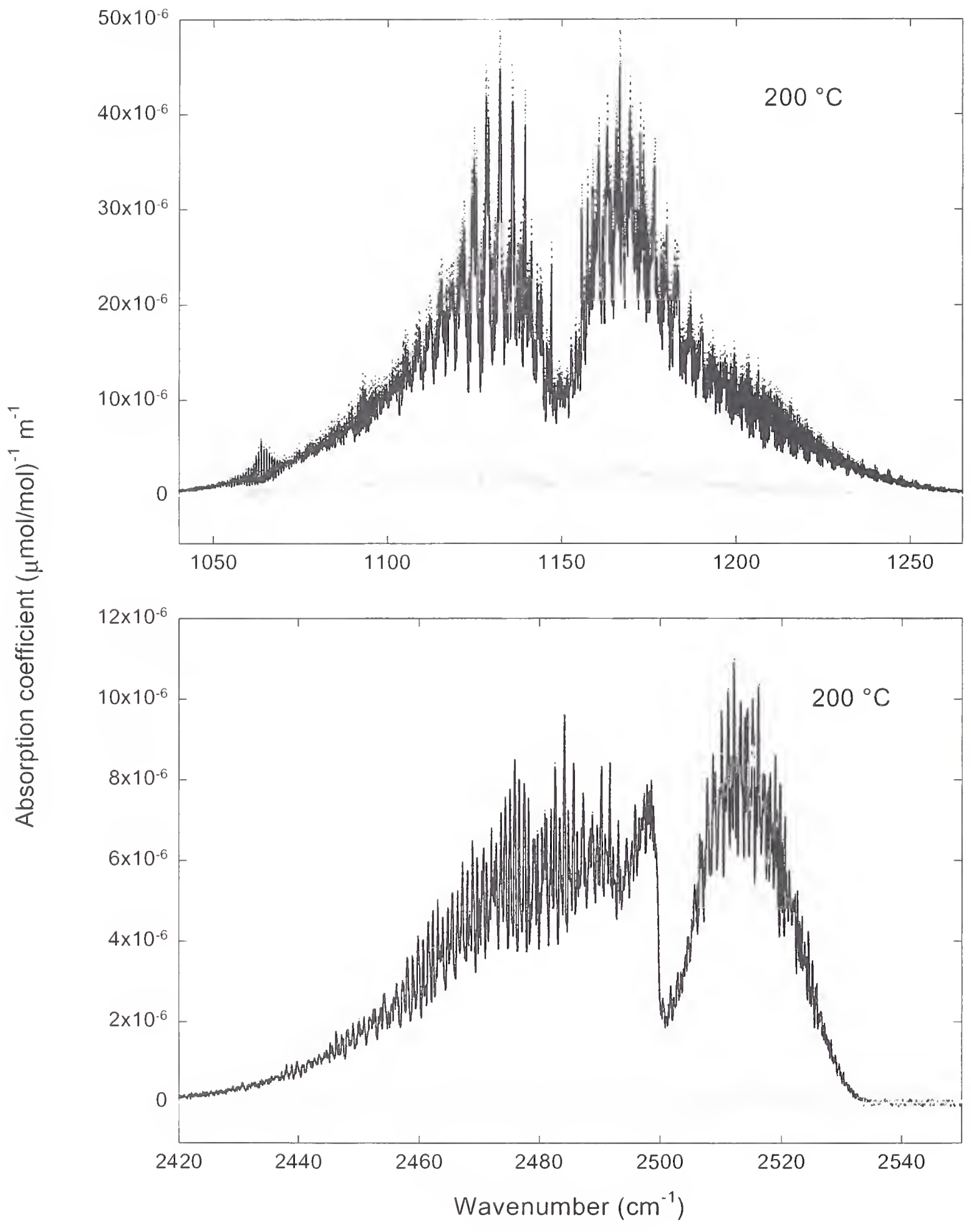

Figure 9b. An overlay of the sulfur dioxide uncorrected ( $\cdots)$ and corrected (-) absorption coefficient spectra along with the difference spectra $(\quad)$ for the $v_{1}$ and $v_{1}+v_{3}$ bands, at $200{ }^{\circ} \mathrm{C}$. 


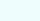


